This item was submitted to Loughborough's Research Repository by the author.

Items in Figshare are protected by copyright, with all rights reserved, unless otherwise indicated.

\title{
The evaluation of new multi-material human soft tissue simulants for sports impact surrogates
}

\section{PLEASE CITE THE PUBLISHED VERSION}

http://dx.doi.org/10.1016/j.jmbbm.2014.09.018

\section{PUBLISHER}

(c) Elsevier Ltd

\section{VERSION}

AM (Accepted Manuscript)

\section{PUBLISHER STATEMENT}

This work is made available according to the conditions of the Creative Commons Attribution-NonCommercialNoDerivatives 4.0 International (CC BY-NC-ND 4.0) licence. Full details of this licence are available at: https://creativecommons.org/licenses/by-nc-nd/4.0/

\section{LICENCE}

CC BY-NC-ND 4.0

\section{REPOSITORY RECORD}

Payne, Tom, Sean Mitchell, Richard Bibb, and Mark Waters. 2014. "The Evaluation of New Multi-material Human Soft Tissue Simulants for Sports Impact Surrogates”. Loughborough University. https://hdl.handle.net/2134/16595. 


\title{
Title: The Evaluation of New Multi-Material Human Soft Tissue Simulants for Sports Impact Surrogates
}

\section{Authors:}

Thomas Payne, Sports Technology Institute, Loughborough University, UK

Dr. Sean Mitchell*, Sports Technology Institute, Loughborough University, UK

Dr. Richard Bibb, Loughborough Design School, Loughborough University, UK

Prof. Mark Waters, School of Dentistry, Cardiff University, UK

*Tel.: +44(0)1509 564804; Fax: +44(0)1509 564801; E-mail: s.r.mitchell@lboro.ac.uk

\begin{abstract}
Previous sports impact reconstructions have highlighted the inadequacies in current measures to evaluate the effectiveness of personal protective equipment (PPE) and emphasised the need for improved impact surrogates that provide a more biofidelic representation of human impact response.

The skin, muscle and subcutaneous adipose tissues were considered to constitute the structures primarily governing the mechanical behaviour of the human body segment. A preceding study by Payne et al. (2014) investigated the formulation and characterisation of muscle tissue simulants. The present study investigates the development of bespoke blends of additive cure polydimethysiloxane (PDMS) silicones to represent both skin and adipose tissues using the same processes previously reported. These simulants were characterised mechanically through a range of strain rates and a range of hyperelastic and viscoelastic constitutive models evaluated to describe their behaviour.

To explore the worth of the silicone simulants, finite element (FE) models were developed using anthropometric parameters representative of the human thigh segment derived from the Visible Human Project. The multi-material silicone construction was validated experimentally and compared with both organic tissue data from literature and commonly used single material simulants: Dow Corning Silastic 3480 series silicones and ballistics gelatin under a representative sports specific knee impact. Superior biofidelic performance is reported for the PDMS silicone formulations and surrogate predictions.
\end{abstract}

\section{Keywords}

Polydimethysiloxane, surrogate, sports, impact, simulant, FEA, thigh, silicone 


\section{Highlights}

- Bespoke PDMS silicones were formulated for skin and adipose

- Materials characterised to determine behaviour at a range of strain rates

- FE models generated using hyperelastic and viscoelastic constitutive models

- FE models validated for PDMS surrogates and previous single material simulants

- PDMS model show more biofidelic impact response compared to other simulants

\section{Introduction}

\subsection{Background}

In sports, impact injuries are a common occurrence. Human surrogates are required to provide both an assessment of injury risk and evaluation of the effectiveness of personal protective equipment (PPE). Artificial impact surrogates are widely used for this purpose and can be broadly divided into two categories: computational and synthetic surrogates.

Within the sporting goods industry, synthetic surrogates are required to provide a physical interface to affix PPE and evaluate real damage mechanisms. The surrogates must also be capable of providing feedback of the mechanical phenomena occurring through instrumentation; this is commonly in the form of pressure films, strain gauges, load cells and accelerometers. However, synthetic surrogates can be expensive and experimental trials can be time consuming. The instrumentation generally offers a partial performance assessment and can introduce artificial stress concentrations affecting the biofidelity of the surrogate.

Computational finite element (FE) models present a method of studying complex mechanical interactions without introducing artificial foreign bodies and can provide a more continuous description of tissue behaviour (e.g. stress profiles). Superior research in this field is, therefore, likely to be based on complimentary mutually validating synthetic and computational human surrogate models providing a greater confidence in each of the approaches (Payne et al., 2013).

Current synthetic impact surrogates are typically categorised as either "durable” or "frangible”. Non-frangible surrogates often differ by industry application and either use stiff, durable materials, relying on instrumentation to assess rigid segment response with respect to organ damage (e.g. automotive crash test dummies) or use a combination of a stiff skeletal component and a single durable simulant to represent the composite response of all soft tissues. Mechanical sports impact surrogates have previously used Silastic 3480 series (Dow Corning Corporation, Michigan, USA) silicones (Hrysomallis, 2009) as single soft tissue simulants and they have since been used elsewhere in industry. Alternatively, frangible surrogates offer greater biofidelity but are intended for single use and predominantly exploit visible damage modes to indicate potential human injuries. In the military, ballistics gelatin has served as a universal soft tissue simulant for several decades (Fackler, 1988; Sellier \& Kneubuehl, 1994) and is either mixed in 10\% (FBI protocol, Fackler, 1988) or 20\% (NATO protocol) gelatin concentrations (by mass). 
It is suggested that these single soft tissue material constructions overlook important mechanical phenomena experienced between soft tissue layers such as variable stiffness, relative movement between structures, pressure distribution and deformation of tissues distant from the impact site. For the sporting goods industry it is believed that a durable mechanical surrogate presents the best method for practically evaluating PPE. A list of desirable characteristics for an effective sports impact surrogate was outlined by Payne et al. (2013):

- Tissue structure biofidelity: the surrogate needs to represent the key human structural elements so specific injury outcomes can be explored.

- Tissue impact response biofidelity: the structures should have comparable strength and stiffness properties to approximate human behaviour on impact.

- Instrumentation capabilities: to provide accurate feedback mechanisms to correlate the impact parameters to specific injury outcomes.

- Durability: capable of providing consistent results from repeated impacts.

Skin, muscle and subcutaneous adipose tissues are considered the primary soft tissue structures governing the mechanical impact response of the human body in fleshy regions prone to bruising. It is proposed that a multi-material surrogate embodying a combination of these tissues can elicit a more biofidelic impact response.

A preceding study by Payne et al. (2014) showed the potential of using polydimethysiloxane (PDMS) silicones to match specific mechanical properties of human muscle. The current study presents an investigation into the benefits of a multi-material surrogate when compared to previously used single material simulants. Adipose and skin simulants have been fabricated and mechanically tested using the procedures outlined in Payne et al. (2014). The mechanical behaviour of both simulants have been characterised using a range of hyperelastic material models and a viscoelastic Prony series. The worth and external validity of the multimaterial surrogate has been demonstrated using FE models comparing single material constructions to multi-material models. Simple, cost effective, single and multi-material puck specimens have been constructed physically and the accuracy of corresponding puck FE model predictions for sport relevant impact performance established. The potential benefits of a simplified multi-layer thigh-segment surrogate have been explored using a more complex FE model subjected to a knee-on-thigh impact, with reference to idealised human tissue behaviour predictions and alternate surrogate material alternatives, to establish the merit of further research to develop a superior physical multi-layer human thigh surrogate.

\subsection{Structure and Composition of Organic Tissues}

\subsubsection{Skin}

Skin is the outermost layer of tissue on the human body and represents a protective barrier from mechanical trauma and stiff interface surrounding other tissues (Edwards \& Marks, 1995; Pailler-Mattei et al., 2008). With the exception of muscle and skeletal tissues it represents the largest organ, constituting approximately 5.5\% of body mass (Goldsmith, 1990). It consists of two major structures, the dermis and epidermis, though the structural 
response is largely determined by the dermal layer, which is primarily populated by collagen fibres (75\% of dry weight). The fibres at rest are twisted and knotted in a very complex network with interspersed elastin fibres and lymphatic elements (Pailler-Mattei et al., 2008; Wu et al., 2003); this makes the fibres very stiff in tension but able to carry little load in compression. Skin properties are greatly inhomogeneous, non-elastic, time-dependent and in a state of biaxial tension in vivo. Its properties are based on the concentration and the orientation of the collagen fibres (Edwards \& Marks, 1995; Wu et al., 2003; Flynn \& McCormack, 2008; Lim et al., 2011; Ní Annaidh et al., 2012).

Most skin characterisation studies have been conducted on porcine tissue which has been shown to exhibit comparable histological, physiological and structural properties to humans (Schmook et al., 2001; Avon \& Wood, 2005; Shergold et al., 2006). The mechanical behaviour observed is influenced by many factors relating to both the specimen and loading conditions. Skin exhibits significant anisotropy underpinned by the presence of Langer lines which describe natural lines of pre-tension in the skin and have a significant effect on the mechanical response (Edwards \& Marks, 2005; Ní Annaidh et al., 2012). Liu \& Yeung (2008) observed a greater stress relaxation in specimens cut perpendicular to the fibre direction and a greater viscoelasticity at higher strains. Similarly Ankersen et al. (1999) and Lim et al. (2011) observed a clear distinction in material stiffness in tensile tests between the two orthogonal directions. The age of the mammalian surrogate is also a pertinent consideration; the collagen content of skin decreases with age and young skin is typically less protective against large strain trauma than older skin which has a proportionally greater elastic region. Older skin also has a lower water content, which has a significant effect on its viscous response (Potts et al., 1984). The location from which the specimens are taken has also been shown to have a significant effect on properties (Haut, 1989; Sugihara et al., 1991; Ní Annaidh et al. 2012).

The loading conditions such as mechanical loading type, loading rate and temperature can also influence response. The morphology of the tissue results in loading type dependent behaviour whereby skin exhibits a greater stiffness in compression than in tension (Lanir \& Fung, 1974; Dunn et al., 1985), though this response can differ between in vivo and in vitro studies. The mechanical properties of skin are also highly dependent on loading rate (Finlay, 1978; Potts et al., 1984; Jamison et al., 1968). At high loading rates a more viscous response has been observed (Jee \& Komvopoulos, 2014), perhaps due to an increased fluid (blood, water, lymph) loss from the compressed dermis (Edwards \& Marks, 1995).

The typical stress-strain response of skin can be divided into three regions described by Brown (1973). In the initial region, the skin is compliant and large deformation occurs at low applied loads with the fibres largely unaligned, the constitutive response at this phase is largely governed by the bending stiffness of collagen fibres and viscous shear between the fibres and extrafibrillar matrix (Cohen et al., 1976). The second phase, the stiffness gradually increases as fibres align themselves in the direction of the load and in the third phase skin behaves almost linearly with the stiffness increasing rapidly as the collagen fibres are mostly aligned and the response becomes dependent on the tensile mechanical response of the collagen fibres which are three orders of magnitude stiffer than the elastin fibres (Ní Annaidh 
et al., 2012); this region has been suggested as occurring at approximately 0.4 strain (Comley \& Fleck, 2012).

Due to its thickness skin is commonly tested in tension (Wu et al., 2003) and under quasistatic loading conditions (e.g. Ankersen et al., 1999; Ní Annaidh et al., 2012), though quasistatic responses may not be simply extrapolated to high strain rates without experimental validation. Lim et al. (2011) and Gallagher et al. (2012) conducted dynamic tensile testing on porcine and human skin tissues respectively using a modified Split Hopkinson Pressure Bar (SHPB). A significant strain rate dependency was observed in both sets of tests, though there was a significant difference in the magnitude of stiffness reported, which has varied widely between previous studies. Few studies have been reported on skin tissues in compression in vitro; Wu et al. (2003) conducted in vitro compressive tests on porcine tissues from the upper neck and back and Shergold et al. (2006) tested porcine rump skin in uniaxial compression. Data from a subset of representative studies are shown in Figure 1.

Figure 1 - Engineering stress-strain graphs for a range of organic skin tissue samples at different strain rates ( $T$ transverse; L - longitudinal)

\subsubsection{Subcutaneous Adipose Tissue}

Subcutaneous adipose tissue, also known as the hypodermis, is a connective fatty tissue located between the dermis and the aponeuroses and fascia of muscles, and is bonded strongly to the dermis. It plays an important role as a mechanical load absorbing and distributing member that absorbs shock and protects against local stresses (Robbins et al., 1989; Miller-Young et al., 2002; Geerligs et al., 2008; Sims et al., 2010; Comley \& Fleck, 2012; Alkhouli et al., 2013). Adipose consists of 90-99\% triglyceride, with the remaining tissue containing 5-30\% water and 2-3\% proteins (Albright \& Stern, 1998). The tissue is a loose association of lipid filled cells called white adipocytes ( $80 \mu \mathrm{m}$ diameter approximately) held in two extracellular networks of collagen fibres penetrated by fibroblasts, neural and vascular cells, and multipotent progenitor cells (Geerligs et al., 2008; Young \& Christman, 2012; Sommer et al., 2013). The smaller network is a reinforcement basement membrane, comprised of collagen fibres, which acts as the walls of a closed cell foam with the adipocyte forming the cavity. The larger network is called the interlobular septa comprised of type I collagen fibres and is roughly $1 \mathrm{~mm}$ in size acting as an open celled foam (Comley \& Fleck, 2010). Adipose, as with most biological tissues, exhibits heterogeneous, rate-dependent, viscoelastic behaviour and experiences large non-linear deformations (Holzapfel, 2004; Sapozhnikov \& Ignatova, 2013). It is suggested that adipose is approximately isotropic in structure and due to the large liquid content is almost incompressible (Samani et al., 2003; Comley \& Fleck, 2010), though a recent study by Sommer et al. (2013) observed some anisotropy in specimens.

In comparison to the relative wealth of research on the mechanical properties of skin, there is a paucity of studies characterising the response of adipose. Much of current research only presents linear material parameters (e.g. Young's modulus) at quasi-static strain rates whilst it is widely documented that the tissue exhibits a non-linear response and significant rate 
dependence (Comley \& Fleck, 2012; Samani \& Plewes, 2004; Alkhouli et al., 2013; Sommer et al., 2013).

Adipose is commonly characterised using samples from the human heel pad region (MillerYoung, et al., 2002; Erdemir et al., 2006; Natali et al., 2013), though fat pads on the hands and feet differ from subcutaneous tissues elsewhere in the body as they contain higher ratios of unsaturated versus saturated fatty acids (Geerligs et al., 2008). They also have morphological differences due to their anatomical function and high levels of stress experienced in normal loading conditions (Gefen \& Haberman, 2007). In the heel pad, fat tissue is separated in a honeycomb structure of compartments (Fontanella et al., 2012).

Adipose properties have also been characterised using samples from human breast tissues (e.g. Azar et al., 2002; Krouskop et al., 1998; Van Houten et al., 2003; Sarvazyan et al., 1994; Samani et al., 2007) or porcine subcutaneous specimens (e.g. Geerligs et al., 2008; Comley \& Fleck, 2010; Comley \& Fleck, 2012), which have been shown to exhibit similarities in morphology, histology, and overall mechanical response with human tissues (Douglas et al., 1972; Paus et al., 2007).

Under compression adipose tissue has low stiffness initially ( $<0.3$ strain) but then under higher loads the collagen fibres of fat and skin come under tension, restricting the movement of the adipose and increasing the stiffness (Miller-Young et al., 2002; Fontanella et al.,2012). This observation is supported by Alkhouli et al. (2013) who reported a mean elastic modulus of $1.6 \pm 0.8 \mathrm{kPa}$ up to 0.3 strain and a mean elastic modulus of $11.7 \pm 6.4 \mathrm{kPa}$ from 0.3 strain to failure. This theory was extended by Sapozhnikov \& Ignatova (2013) who suggested that between 0.4-0.5 strain, adipose exhibits a non-linear behaviour followed by a transition section between 0.5-0.7 strain where stresses decrease attributed to the collapse of cell walls, with an expulsion of fluid. This is then followed by a hardening with a rapid unlimited increase in compressive stress governed by the stiffness of the remaining cell shells.

Under quasi-static strain rates, studies have shown the elastic modulus of adipose to be approximately between 1-4.5kPa (Azar et al., 2002; Samani \& Plewes, 2004; Samani et al., 2007; Sims et al., 2010; Comley \& Fleck, 2012) with little strain rate sensitivities between $2 \times 10^{-3}-10 s^{-1}$ (Comley \& Fleck, 2012). Beyond $10 \mathrm{~s}^{-1}$, significant sensitivity has been observed (Miller-Young et al., 2002; Gefen \& Haberman, 2007; Comley \& Fleck, 2012). Comley \& Fleck (2012) reported an increase in Young's by three orders of magnitude from $2 \mathrm{kPa}$ at $10 \mathrm{~s}^{-1}$ to $4 \mathrm{MPa}$ at $3000 \mathrm{~s}^{-1}$, a similar modulus to the dermis. Comparable responses were observed by Egelbrektsson (2011) when conducting high strain rate compressive tests. Representative stress-strain data from a subset of characterisation studies are shown in Figure 2.

Figure 2 - Compressive engineering stress-strain graphs for a range of organic adipose tissue samples at different strain rates in (a) linear and (b) log-linear plots

\subsection{Aims and Objectives}

Previously used surrogate materials do not accurately simulate human skin or adipose tissue structure or response. Their anisotropic, inhomogeneous, location, strain and strain rate 
dependent impact response behaviour is not accurately reproduced. Given inadequacies in current surrogates and measures of assessing PPE effectiveness (outlined in Payne et al., 2014) there is a significant gulf between the current state-of-the-art durable surrogates and a fully biofidelic human surrogate.

A worthwhile intermediate step is to develop more biofidelic isotropic silicone materials which both provide improved accuracy of predictions and serve as a stepping stone to more biofidelic anisotropic materials. It can be argued that for specific applications a more limited level of biofidelity is adequate, in terms of injury related response phenomena simulation, and desirable, in terms of surrogate cost. The synthetic surrogate materials proposed in this study do not address the issue of anisotropy or local homogeneity. The materials are formulated in an attempt to exhibit superior biofidelity (especially in terms of strain and strain rate dependencies) for specific tissue types and to exhibit superior response distribution between tissue regions when assembled to form a multi-layer surrogate. The further worth of anisotropic material development can then be explored in a later study.

FE models can be effectively used as a diagnostic and predictive design tool to understand surrogate impact behaviours without having to construct expensive prototypes. In this study FE models have been used to provide an indication of predicted human impact behaviour through consideration of the compressive mechanical properties of key organic tissues from literature. This has enabled a comparison of the effectiveness of different materials.

The key research questions addressed by this study are:

i. Can PDMS materials be fabricated that provide a better representation of organic skin and adipose tissues than other, commonly used, alternate simulant materials?

ii. Can experimental material characterisation, constitutive material modelling and dynamic FE load/deformation simulation techniques be used to accurately predict the performance of single and multi-material surrogate constructions using common and newly formulated synthetic surrogate materials?

iii. Does a multi-material PDMS silicone surrogate have the potential to mimic more closely multi-tissue organice human structures than current single surrogate material apporaches?

\section{Methodology}

\subsection{Simulant Formulation and Characterisation}

\subsubsection{Formulations}

PDMS silicones were formulated using the techniques established in Payne et al. (2014). The silicone constituent parts were weighed and mixed manually prior to degassing in a vacuum chamber. The silicones were poured in an ASTM Standard D395 (2008) compressive specimen mould and cured in an environmental chamber at $90^{\circ} \mathrm{C}$. The Part A and B PDMS silicone concentrations for skin and adipose simulants are shown in Table 1. 


\subsubsection{Low Strain Rate Mechanical Tests}

The preceding study by Payne et al. (2014) describes the testing procedures used to characterise the simulants. Low strain rate uniaxial compressive tests were conducted using an Instron 5569 screw-driven test machine. Tests were performed using a cyclic compressive protocol incrementally increasing the applied strain in 0.1 strain intervals to failure at a constant strain rate of $0.4 \mathrm{~s}^{-1}$. Intermediate strain rate compressive tests were conducted using an Instron 9250 drop tower using a 6.8kg linear guided drop mass from a range of heights. The material response is recorded using three piezoelectric load cells in the base of the bottom compressive platen whilst the displacement of the specimen was recorded using high speed video. Stress relaxation tests were also performed on an Instron 5569 using a rampand-hold compression test applying 0.5 strain to the specimen for $300 \mathrm{~s}$.

As an initial point of comparison, the quasi-static uniaxial compressive responses of organic skin and adipose tissues were compared to a range of commonly used soft tissue simulants (Fig. 3). Figure 3 shows that skin is significantly stiffer than any simulant and adipose is significantly softer than any other simulant, particularly at strains greater than 0.1 .

Figure 3 - Quasi-static stress-strain graphs showing the uniaxial compressive responses of organic adipose (Comley \& Fleck, 2012) and skin (Shergold et al., 2006) tissues compared to soft tissue simulants in (a) linear and (b) log-linear graphs

The quasi-static PDMS skin simulant response was compared to the best alternate simulant single material simulant (Silastic 3481) (Fig. 4). The PDMS skin simulant showed a consistently improved response compared to Silastic 3481 exhibiting differences between 84$90 \%$ of the organic tissue properties, whilst the Silastic simulant exhibited differences between $89-96 \%$.

Figure 4 - Quasi-static stress-strain graphs for: (a) PDMS skin simulant compared to organic tissue (Shergold et al., 2006) and (b) Silastic 3481 simulant compared to organic skin tissue (Shergold et al., 2006)

The quasi-static responses of the PDMS adipose simulant is compared with organic tissue properties alongside the best alternate single material simulant (10\% gelatin) (Fig. 5). The $10 \%$ gelatin simulant shows significant divergence from the target organic tissue dataset with an error of up to $1855 \%$ at 0.16 strain. The PDMS simulant exhibits a much closer response with a maximum of $239 \%$ error at 0.06 strain decreasing to $0 \%$ error at 0.23 strain.

Figure 5 - Log-linear quasi-static stress-strain graphs for: (a) PDMS adipose simulant compared to organic tissue (Comley \& Fleck, 2012) and (b) 10\% gelatin simulant compared to organic adipose tissue (Comley \& Fleck, 2012)

The extent of the Mullins effect has been investigated with the percentage reductions in stress from cyclic compressive tests at maximal strain recorded. The skin simulant experienced a significantly lower stress softening effect than the adipose tissue simulant with percentage reductions of $3.9 \%$ and $13.5 \%$ respectively. 
The poissons ratio of each simulant has been determined using high speed video of an ASTM D395 specimen in compression using the methods outlined in Payne et al. (2014). Both tissue simulants were determined to be quasi-incompressible with ratios of 0.476 and 0.492 for skin and adipose simulants respectively.

\subsubsection{Intermediate Strain Rate Mechanical Tests}

Intermediate strain rate tests were performed using a drop tower and high speed video analysis to determine the material response under more dynamic loading conditions. The stress-strain plots at a range of strain rates are shown in Figure 6. The strain rates reported are characterised by the initial maximum value recorded; the differences in strain rate between materials varies due to differences in displacement rate.

Figure 6 - Intermediate strain rate engineering stress-strain curves for: (a) PDMS skin simulant and (b) PDMS adipose simulants

At intermediate strain rates, the responses of the PDMS skin and adipose simulants were compared with the higher strain rate responses of the respective organic tissues by Shergold et al. (2006) and Comley \& Fleck (2012); the banded lines indicate the PDMS responses (Fig. 7).

The responses of the PDMS skin tissue simulant falls within the response corridor outlined by the organic tissues. The adipose simulant, however, exhibited a greater stiffness than the organic equivalent, in particular at low strains and high strain rates. The organic tissues also appear to exhibit a greater strain hardening than the PDMS silicones at approximately 0.15 strain.

Figure 7 - Log-linear engineering stress-strain graphs showing a comparison between PDMS simulants and organic tissue data at intermediate strain rates for: (a) skin and (b) adipose tissues

\subsubsection{Stress Relaxation Tests}

The viscoelasticity in the simulants was also determined using uniaxial stress-relaxation tests. The relative differences in viscoelasticity are illustrated in normalised stress-time plots in Figure 8 where it is clearly shown that the adipose simulant exhibited a far greater relaxation than the skin simulant.

Figure 8 - Normalised stress-time plot showing stress relaxation in PDMS skin and adipose tissue simulants

\subsection{Constitutive Modelling}

Hyperelastic and viscoelastic material models were used to describe the simulant materials. Mooney Rivlin, Ogden and Neo Hookean hyperelastic models were fitted to the experimental data using the automated generator in Abaqus Explicit solver (Version 6.13). The material fits for both materials are shown in Figure 9 alongside Table 2 showing the degree of 
divergence of each FE material prediction from the experimental data with root mean square (RMS) error values recorded to quantitatively show the closeness of fit.

Figure 9 - Hyperelastic model fits for: (a) PDMS skin simulant and (b) PDMS adipose simulant at a range of intermediate strain rates

The Ogden model generally provides the best description of the skin simulant which exhibits a significant strain hardening effect; this is most notable at $134 \mathrm{~s}^{-1}$ (0.311 RMS error). However, the softer adipose simulant, which experienced less strain hardening, is better represented by the Mooney-Rivlin model ( $<0.01267$ RMS error).

Table 2 - Hyperelastic model coefficients for PDMS skin and adipose tissue simulants

A Prony series was also calculated for both simulants using data from the uniaxial stress relaxation tests (Table 3). Normalised shear modulus values were calculated from stressstrain data and used to generate time-dependent Prony series parameters in the automated feature of the FE solver which fits a curve to the stress relaxation data

Table 3 - Prony series coefficients for PDMS skin and adipose tissue simulants

\section{3. $\quad$ Finite Element Models}

\subsubsection{Overview}

Finite element models were developed to illustrate the relative benefits of multi-material models compared to single material constructions. It is acknowledged that, the finite element models used only provide a very simplified representation of a limb segment, however their simplicity lends clarity to the observation of different impact responses when more or less representative organic tissue or synthetic surrogate material models are employed.

Two different surrogate geometries were designed: the first, a simple cylindrical puck to enable the cost effective experimental validation of the FE modelling methods; the second, a cylindrical thigh segment to predict the benefits of developing a multi-layer limb segment surrogate before incurring the expense of overcoming the manufacturing difficulties.

\subsubsection{Geometric Parameters}

A 130mm diameter layered cylindrical puck was designed to permit cost effective experimental validation under laboratory drop test conditions. A 150mm diameter cylindrical surrogate was used to approximate the human thigh segment.

Surrogate dimensions (e.g. skin thickness) were determined from human anthropometric parameters derived from measurement of axial CT scans of a $50^{\text {th }}$ percentile US male from the visible human project (VHP, US National Library of Medicine). Distances from the bone centroid to tissue interfaces were sampled at 8 evenly distributed points on the cross section. This was performed at 5 sections through the length of the thigh region on the visible human project male scan and was used to infer average tissue distances from the bone centroid and 
hence thicknesses. The surrogate was given a length of $276 \mathrm{~mm}$ as it represents the largest fleshy area visible on the VHP scans where there were no other conflicting skeletal tissues (e.g. pelvis or patella bones). The surrogate geometry and dimensions are shown in Figure 10, the bone ends were rigidly constrained in all translational directions.

Figure 10 -Surrogate geometric configurations for: (a) layered puck and (b) cylinder models

\subsubsection{Material Models}

Published organic tissue data for skin and adipose (Fig. 2, Fig. 3) and muscle tissue datasets presented in the preceding study (Payne et al., 2014) were used as the initial basis for model definition. Relaxed muscle tissues were used instead of contracted as the impacts are believed to be more prevalent and serious when the participant would not be anticipating the impact. Data at representative intermediate strain rates for sports impact scenarios derived from cylindrical impact simulation of organic tissues were selected and used to populate material models (Fig. 11).

Figure 11 - Engineering stress-strain graphs showing the organic tissue and PDMS simulant data used in FE simulations in: (a) relaxed muscle; (b) subcutaneous tissue; (c) skin

As previously discussed ( $\S 1.2 .2$ ), the organic tissue behaviour was simplified to exhibit isotropy and incompressibility. Hence, single term Ogden models proposed by Shergold et al. (2006) and Comley \& Fleck (2012) in the $20-260 \mathrm{~s}^{-1}$ strain rate ranges were used to describe the compressive behaviour of the skin and adipose respectively. An Ogden model was created for muscle tissue using the dataset from the previous study from McElhaney (1966) and Song et al. (2007). The mechanical properties of bone were adapted from a quasi-static compressive experiment conducted by McElhaney (1966) on cortical bone. Cortical bone is significantly stiffer than trabecular bone (Rho et al., 1993) and it is believed that this constitutes a more significant part of the overall tissue response and is therefore deemed appropriate as an initial simplification; an Ogden model fit for cortical bone is similarly detailed in Table 4. The densities of the materials are also presented.

Table 4 - Single term Ogden model coefficients for: skin (Shergold et al., 2006); adipose (Comley \& Fleck, 2012); relaxed muscle (McElhaney, 1966; Song et al., 2007); cortical bone (McElhaney, 1966) and material densities for each organic tissue

The viscoelastic properties of organic soft tissues are presented in the form of Quasi-Linear Viscoelastic (QLV) Prony Series (Table 5) using data adapted stress relaxation tests on skin (Wu et al., 2003); adipose (Gefen \& Haberman, 2007) and relaxed muscle (Van Loocke et al., 2009).

Table 5 - Prony series coefficients for organic skin, adipose and relaxed muscle tissues 
The PDMS material models for each of the tissue structures at relevant strain rates are shown in Table 6.

Table 6 - Hyperelastic and viscoelastic material coefficients for PDMS silicones

Silastic 3480 series silicones have previously been used to represent human soft tissues. 3481, 3483 and 3487 two-part cure silicone elastomers were fabricated in the same manner as the PDMS silicones and characterised through a range of strain rates. Similarly, ballistics gelatin was formulated in 10 and 20\% concentrations using the procedure outlined by Jussila (2004) and tested in the aforementioned manner. Data used to populate each of the hyperelastic material models are shown in Figure 12 with Mooney-Rivlin model coefficients and viscoelastic Prony series coefficients detailed in Table 7.

Figure 12 - Compressive engineering stress-strain graphs of Silastic simulants and ballistics gelatin at representative intermediate strain rates

Table 7 - Hyperelastic Mooney-Rivlin model coefficients and Prony series coefficients for single material simulants

\subsubsection{Sports Impact Scenarios}

A high-mass, low-velocity knee-on-thigh human impact similar to that which may be experienced in rugby or basketball gameplay was simulated using a 72mm diameter, $3 \mathrm{~kg}$ hemispherical geometry with an initial velocity of $3 \mathrm{~ms}^{-1}$ (Halkon et al., 2014).

\subsubsection{Model Definition}

The 3D surrogate geometries were discretised using second order C3D8R hexagonal brick elements due to their low computational cost and high rate of convergence. The reduced number of integration points per element also alleviates convergence for nearly incompressible materials (Podnos et al., 2012). Due to the dynamic nature of impacts, mesh densities were refined dependent on their master and slave assignments. Slave surfaces were assigned a finer mesh density to prevent coarse mesh discretisation, element distortion and penetration of surfaces. To avoid hourglassing and artificial results, four continuum solid elements were created through the thickness of the skin layer, this was used in combination with enhanced hourglass control to stabilise the contact and reduce artificial energies. All meshes were checked to ensure the maximum angle was no greater than $120^{\circ}$, minimum angle was no less than $20^{\circ}$ and the element size was not less than $50 \%$ of the target size. The tissue layers were assigned nominal element sizes of: $3 \mathrm{~mm}, 2 \mathrm{~mm}, 4 \mathrm{~mm}$ and $3 \mathrm{~mm}$ for skin, adipose, muscle and bone respectively (Fig. 13).

Figure 9 - Cylindrical surrogate mesh density

Impactors were treated as rigid bodies due to the large difference in stiffness between the impactor and surrogate and the anticipated small magnitude of displacements. This increases 
the computational efficiency as no element calculations are required for the impactor body. The rigid bodies for the knee impactor and cricket ball were given 9,834 and 5,565 tetrahedral element meshes respectively, sufficient to maintain their geometric profile. Only the mass densities of the impactor were then required to govern their mechanical behaviour.

A surface-to-surface kinematic contact with pure master and slave surfaces was employed for the impactor and skin interaction. An exponential pressure-overclosure relationship was enforced defining normal behaviour with a pressure at zero overclosure of $100 \mathrm{kPa}$ and a clearance at zero pressure of $1 \times 10^{-4} \mathrm{~m}$. A critical damping fraction of 0.1 was also employed in both the normal and tangential directions. A frictional coefficient of 0.75 was used to define the tangential behaviour with finite sliding parameters. The other tissue layers were tied together using the penalty method for reduced computational cost of the contact interaction and to represent the adhesion between tissue layers in the human body (e.g. skin and adipose). Previous organic tissue modelling studies have similarly considered the interactions between the bone-muscle and skin-fat layers in this manner (Rohan et al., 2013).

A time step of $0.04 \mathrm{~s}$ was used in the simulation with mass scaling to a minimum time increment of $1 \times 10^{-6} \mathrm{~s}$ to reduce the computational time of interactions and prevent element distortion. The adipose layer experiences significantly greater strains than other tissues due to its softness. As a result, an element distortion control of 0.1 was employed in this layer, which will restrict the deformation of the elements at 0.9 nominal strain. It is noted that care must be taken when interpreting results with this artificial deformation constraint; however in this instance it is necessary for numerical stability and convergence. Wang et al. (2006) suggested that as a general rule the kinetic energy of the deforming material should not exceed a small fraction (5-10\%) of the internal strain energy. The relative internal and artificial energies from the simulation is shown in Figure 14.

Figure 10 - Artificial energy/internal energy vs. time graphs for knee impact in an organic tissue cylinder surrogate

\section{Experimental Validation of FE Models}

\subsection{Background}

To ensure that FE model predictions are accurate and believable, experimental validations have been performed. It is a common strategy to initially validate FE predictions against simplified structures and geometries and refine the findings to more complex systems (Tiossi et al., 2013).

\subsection{Test Methodology}

Material drop tests were performed on a series of puck shaped surrogates simulating a highmass, low-velocity knee-on-thigh human impact similar to that which may be experienced in rugby or basketball. This was approximated using a $72 \mathrm{~mm}$ diameter, $3 \mathrm{~kg}$ impactor with an initial velocity of $3 \mathrm{~ms}^{-1}$ using parameters defined by Halkon et al. (2014). 130mm diameter puck surrogates were fabricated for each of the simulant materials: Silastic 3481, 3483, 3487, $10 \%$ gelatin, $20 \%$ gelatin and PDMS formulations. 
The impactor was dropped from a height of $0.5 \mathrm{~m}$ through a guidance system onto the puck surrogate, which was positioned on a Dytran 1061V load cell (Dytran Instruments, USA). High speed imaging was also captured with a Photron Fastcam DA1 675K-C1 high -speed video camera (Photron Limited, USA) positioned perpendicular to the surrogate and recorded at 5000 frames per second with an image resolution of 1024x1024 pixels.

Four trials were conducted for each surrogate type with displacement-time and force-time outputs calculated from the video and load cell data. The experimental results were then compared with the predicted outputs from the FE models.

\subsection{Validation Results}

Initial FE predictions indicated divergences of up to $42 \%$ from experimental data when using previously defined material models. An investigation into the specific properties of the individual material batches used in the puck surrogates showed some process-induced variability ( $<15 \%$ stiffness) in mechanical response. The mechanical properties from the batch material were then used to populate the FE models. The FE model outputs attained have been compared to experimental data in Figure 15 with the peak displacements $\left(x_{\max }\right)$, time to peak displacement $\left(t_{\max }\right)$, peak force $(\mathrm{RF})$ and time to peak force $\left(t_{\mathrm{rf}}\right)$ presented in Table 8.

Figure 15 - Displacement vs. time and force vs. time graphs showing a comparison between experimental results and FE model predictions in: (a) Silastic 3481; (b) Silastic 3483; (c) Silastic 3487; (d) 10\% Gelatin; (e) 20\% Gelatin and (f) PDMS surrogates

Table 8 - Comparison of peak displacement $\left(x_{\max }\right)$, time to peak displacement $\left(t_{\max }\right)$ force $(\mathrm{RF})$, time to peak force $\left(t_{r f}\right)$ measurements between experimental data and FE model predictions

The 10\% and 20\% gelatin FE model predictions showed a significant divergence from the experimental test data both in terms of displacement and force parameters. Both models exhibited an increased stiffness, therefore the material models were optimised to provide a better representation of the experimental data. In both materials, the hyperelastic material stiffness was reduced to $1 / 3$ of its original stiffness. The resultant model outputs are shown in Fig. 16 compared to experimental data.

Figure 16 - Displacement vs. time and force vs. time graphs showing a comparison between experimental results and optimised FE model predictions for: (a) $10 \%$ gelatin and (b) $20 \%$ gelatin 


\section{Limb Segment Surrogate Design Analysis}

\subsection{Introduction}

The responses of the developed PDMS simulants and single material soft tissue simulants were compared to predicted responses of an identical surrogate constructed from theoretically more biofidelic human tissues based upon the organic tissue material models detailed in Table 4.

A series of mechanical response parameters were selected to evaluate the effectiveness of the limb segment surrogate. The maximum top surface displacement $\left(x_{\max }\right)$ and time to maximum deformation $\left(t_{\mathrm{x}}\right)$ were used as they provide a representation of the overall soft tissue response and the time over which it was achieved. This parameter provides an indication of the nett body segment deformation which relates to soft tissue injury modes and also affects the manner in which the body segment interacts with PPE. The maximal Cauchy stress, $\sigma_{22}$, normal to the direction of impact $\left(\sigma_{22, \max }\right)$ and time to peak stress $\left(t_{\sigma}\right)$ was also recorded on the bone surface as it represents the magnitude of stresses transferred through the soft tissues. In an injury context, this parameter provides an indication of susceptibility to deep tissue injury and mechanical loading of the skeleton.

The maximum von Mises surface stresses $\left(\sigma_{\mathrm{v}, \max }\right)$ and compressions for each of the layers are also a pertinent consideration as they are important to indicate the worth of a layered approach. The layer responses show the load transfer through the surrogate from the impact stimulus and the time course over which they occur. In a sports injury context, the layer effects also provide information on the susceptibility to surface or deep tissue damage and an indication of the differences in responses attained from different body types (e.g. athletic lean vs. sedentary fatty body types).

\subsection{Overall Surrogate Responses}

The maximum top surface displacements at each time interval and the peak stresses on the bone surface at each time interval are shown in Figure 17a and Figure 17b respectively.

Figure 17 - (a) $x_{\max }$ vs. time graph for top surrogate surface; (b) $\sigma_{22, \max }$ vs. time graph on bone surface

The magnitudes of differences in $x_{\max }, \mathrm{t}_{x}, \sigma_{22, \max }$ and $t_{\sigma}$ are shown in Table 9 alongside percentage difference values from the idealised organic model predictions.

Table 9 - Maximum recorded displacement and bone stress values for knee impact simulations (\% difference from organic tissue predictions in brackets)

Sagittal plane sections of the surrogates taken at $x_{\max }$ for PDMS, organic tissues and the most representative single material simulant (10\% gelatin) are displayed in Figure 18 and show the magnitude of compression of the surrogates and associated tissue layers. 
Figure 18 - Images showing surrogate displacement in knee impact simulations in: (a) organic tissues; (b) PDMS; (c) $10 \%$ gelatin; (d) Silastic 3487

\subsection{Individual Layer Responses}

\subsubsection{Surface Stresses}

The von Mises stresses $\left(\sigma_{\mathrm{v}, \max }\right)$ experienced on the skin and muscle layer surfaces of the surrogates are shown in Figure 19.

Figure 19 - $\sigma_{v, \max }$ vs. time graphs for simulant materials on: (a) skin layer surface and (b) muscle layer surface

\subsubsection{Layer Displacements}

The thicknesses of the tissue layers were compared between the organic tissue, PDMS, Silastic 3487 and 10\% gelatin simulants throughout the knee impact in Figure 20.

Figure 20 - Tissue layer thicknesses showing responses through the knee impact simulation: (a) skin; (b) adipose; (c) muscle

\section{Discussion}

\subsection{Organic Tissue Data}

Given the wide range of properties reported it is impossible to define absolutely the behaviour of human soft tissue. However, given representative data for a particular injury scenario (e.g. skin, adipose and muscle characterisation in an appropriate body segment, for a demographic of interest, over a relevant strain rate domain), this study explores whether superior synthetic materials can be developed to produce more biofidelic surrogates for experimental work and more biofidelic complementary constitutive models for computational analysis. The preceding study by Payne et al. (2014) collated organic muscle tissue data from McElhaney (1966) and Song et al. (2007) to provide a representative reference data set to act as a human muscle benchmark. The same approach has been adopted in the present study for skin and adipose tissues. Studies by Shergold et al. (2006) and Comley \& Fleck (2012) provide an indication of the tissue behaviour under compressive loading conditions through a range of strain rates. Each of the tissues was considered as incompressible and isotropic as an initial simplification of their actual behaviour.

There is still, however, a lack data pertaining to the mechanical response of skin and adipose tissues under intermediate strain rates $50-1000 \mathrm{~s}^{-1}$, particularly $250-1000 \mathrm{~s}^{-1}$ believed to be representative of the rates experienced from some sports impacts (e.g. cricket ball projectile). This introduces issues where the responses in this unreported region need to be inferred from data at unmatched strain rates. To better understand the responses of the organic tissues in the strain rate regions of interest further characterisation is required. Testing of organic tissues (e.g. porcine) under the same loading conditions used to characterise the PDMS silicones 
could provide more complete comparative data and a better confidence in the accuracy of the silicones. Nevertheless, the performance of the proposed PDMS formulations is promising.

\subsection{Adipose \& Skin Tissue Simulants}

\subsubsection{Quasi-static Response}

The PDMS skin simulant exhibited a far lower stiffness than the organic tissue dataset at quasi-static strain rates but still provided an improved response compared to the best existing single soft tissue simulant tested (Silastic 3481). Errors of up to 89\% were experienced between the PDMS simulant and organic tissues at 0.4 strain with a decreasing error to $86 \%$ at higher strains. The Silastic 3481 simulant exhibited an initial error of $89.2 \%$ increasing to $97 \%$ at 0.55 strain (Fig. 4). To achieve this modest improvement the PDMS formulation exhibited stiffness almost $3 \times$ greater than Silastic 3481 at 0.55 strain.

The developed PDMS silicones showed an improved quasi-static loading response to the most representative previously used simulants when compared to organic tissues. The PDMS adipose tissue simulant exhibited a $250 \%$ error initially at 0.1 strain and a decreasing error below $150 \%$ this point onwards. The best performing existing simulant (10\% gelatin), showed a far greater divergence from the organic tissue dataset with an error of up to $1855 \%$ at 0.16 strain (Fig. 5). Generally, as noted in the previous study, the silicones tended to exhibit an increased stiffness at low strains compared to organic tissues but exhibit a weaker strain hardening at higher strains.

\subsubsection{Intermediate Strain Rate Response}

At increased strain rates the PDMS skin simulant showed a comparable magnitude of stiffness to organic tissues in similar strain rate ranges (Fig. 7). The PDMS adipose simulant, however, despite showing a more comparable quasi-static response experienced a significantly greater stiffness at increased strain rates within the reported range.

Both PDMS simulants exhibited significant strain rate dependencies, with their maximal stress response increasing by $12.5 \times\left(0.4-194 \mathrm{~s}^{-1}\right)$ and $17 \times\left(0.4-134 \mathrm{~s}^{-1}\right)$ in adipose and skin simulants at 0.5 and 0.3 strain respectively. Previous organic adipose characterisation studies have shown significant non-linear strain rate dependencies. Comley \& Fleck (2012) reported a $4 \times$ increase in maximal stress response between $0.2 \mathrm{~s}^{-1}$ and $250 \mathrm{~s}^{-1}$ and a $680 \times$ increased stress response between $250 \mathrm{~s}^{-1}$ and $2700 \mathrm{~s}^{-1}$ at 0.3 strain. Similarly, Egelbrektsson (2011) reported an increase in maximal stress response of $2 \times$ between $0.2 \mathrm{~s}^{-1}$ and $250 \mathrm{~s}^{-1}$, and an increase of $1344 \times$ between $250 \mathrm{~s}^{-1}$ and $2100 \mathrm{~s}^{-1}$ at 0.3 strain. The present study shows a considerably greater increase in maximal stress between quasi-static and approximately $250 \mathrm{~s}^{-1}$ strain rates. This is a factor that would need to be addressed in further iterations of the PDMS silicone formulations and could potentially be developed for specific sports applications based on the relevant strain rate domains.

Organic skin characterisation studies have typically shown a lower strain rate dependency than adipose. Shergold et al. (2006) reported a $5 \times$ increase in maximal stress between $0.004 \mathrm{~s}^{-1}$ and $40 \mathrm{~s}^{-1}$, and a $3.4 \times$ increase between $40 \mathrm{~s}^{-1}$ and $4000 \mathrm{~s}^{-1}$ at 0.4 strain in compression, 
whilst Lim et al. (2011) reported an increase in maximal stress of $3 \times$ between $0.004 \mathrm{~s}^{-1}$ and $1700 \mathrm{~s}^{-1}$ and an increase of at $1.5 \times$ between $1700 \mathrm{~s}^{-1}$ and $3700 \mathrm{~s}^{-1}$ at 0.2 strain in tension. By comparison, greater magnitudes of maximal stress increases were reported in developed PDMS skin than organic tissue. The initial differences between organic skin and the PDMS simulant under quasi-static loading conditions are compensated by a greater magnitude of strain hardening, which generates comparable behaviour. These results are in contrast to a those found by Shergold et al. (2006) who noted that porcine skin was more strain rate sensitive than silicone rubber and exhibited a greater stiffening at increased strain rates.

\subsubsection{Stress Relaxation Responses}

The viscoelastic properties of the PDMS silicones show large divergences from the organic tissues, in particular skin tissue is not well represented (Fig. 21). Organic skin exhibits significant viscoelastic behaviour, which could potentially be due to the movement of fibres and fluid, which are not present in the silicone structure. This perhaps indicates that the greatest future elastomer advances will not be achieved by revised elastomer formulations but by flexible composite material development instead.

Figure 21 - Normalised stress-time plots showing differences in stress relaxation between PDMS simulants and organic tissues in: (a) skin (Wu et al., 2003); and (b) adipose (Gefen \& Haberman, 2007) tissues

\subsection{Computational Model Responses}

The combined multi-material surrogate responses from the developed PDMS silicones show a significantly improved representation of the predicted organic tissue responses than single material constructions using existing simulants.

The top surface displacements (Table 9) provide a good indication of the composite dynamic impact response behaviour of all of the tissue layers in combination. The PDMS silicones provided better matched levels of overall compression than single material constructions. A difference in $x_{\max }$ of $-1.42 \%$ was recorded between the PDMS simulants and the target organic tissue model. The $10 \%$ gelatin simulant typically provided the closest representation of the $x_{\max }$ of the organic tissue model, however exhibited softer overall behaviour with a $+7.57 \%$ difference from the organic tissue. The Silastic 3487 was the most comparable durable simulant, however exhibited an significantly increased stiffness and a difference in $x_{\max }$ of $-27.4 \%$ from the organic tissue model predictions.

The $\sigma_{22}$ stresses (Table 9) experienced on the bone are pertinent as they are a direct measure of the load transfer through the surrogate from the normal, axial impact. The PDMS silicones exhibited similar $\sigma_{22}$,max profiles on the bone surface to the predicted organic tissue though showed a $-15.2 \%$ difference from the organic tissue model. The $10 \%$ gelatin model provided a closer representation of the $x_{\max }(+9.57 \%)$, though differed in $t_{\sigma}$ by $-15 \%$ compared to just $+4 \%$ exhibited by the PDMS simulant model. The PDMS simulant model also more accurately represents the onset and delay in stresses predicted by the organic tissue model with a significantly elongated $\sigma_{22, \max }$-time trace to all other simulants. 
The importance of a biofidelic skin layer was demonstrated in the surrogate model through $\sigma_{\mathrm{v}, \text { max }}$ experienced on the top surface (Fig. 19a). The responses in the organic tissue and PDMS simulant models show comparable stress profiles with an initial sharp increase in stress followed by a gradual rise to the peak whilst all other simulants exhibited a more simple parabolic response. Although the PDMS skin exhibited a significantly reduced $\sigma_{\mathrm{v}}$,max compared to organic tissues it still provides a much closer match than other single material simulants. The importance of this layer is also emphasised by the lack of compression exhibited in the organic tissue and PDMS skin layers compared to other simulants (Fig. 20a).

The importance of a biofidelic adipose layer is highlighted by the initial rapid decreases in layer thickness shown in Figure 20b. Organic adipose exhibits initially very soft behaviour with a rapidly increasing stiffness at approximately 0.3 strain (§1.2). The organic adipose tissue layer experiences greater initial levels of compression than the PDMS simulant. The PDMS simulant layer, however, experiences an overall greater level of compression than organic tissue, which could be attributed to the lower strain hardening present under high strain deformations. The softer $10 \%$ gelatin simulant exhibits a slower initial displacement than the layered models but a similar level of overall compression to the PDMS simulant model.

Payne et al. (2014) indicated the relative benefits of a biofidelic muscle tissue simulant in uniaxial compression tests. Figure 20c shows the thickness of the muscle tissue layers. The PDMS simulant model provided a close representation of the predicted organic tissue layer response exhibiting similar deformation responses and just a $16 \%$ difference at maximal compression. The $\sigma_{\mathrm{v}, \max }$ experienced on the muscle surface (Fig. 19b) also showed that the PDMS silicone exhibited the closest response to the predicted organic tissue model with a $14.5 \%$ difference compared to a minimum of a $+50.7 \%$ difference in the $10 \%$ gelatin surrogate.

Overall, the simulations showed that the PDMS silicone surrogate was the most biofidelic simulant for all geometries and loading conditions. The $10 \%$ gelatin simulant model was the best alternate single material simulant; however, this material is innately inappropriate for sports impact surrogates due to its frangibility. Frangible surrogates attain permanent damage from impacts, which are not suited to repeat testing required for PPE evaluations.

Consequently, the surrogates are far more expensive per test than their mechanical alternatives and also often require specialised storage conditions and have limited shelf life. Silastic 3487 simulant provided the best existing durable synthetic representation of the multi-material response though still showed significant divergences from the target organic tissue predictions.

All the surrogate responses are compared to an idealised organic tissue model predicting how a human might behave under the same loading conditions. This is an essential aspect of the modelling approach and it is necessary to have a worthwhile and believable organic tissue model. Although, it is accepted that this is a simplification of actual human behaviour as some tissue complexities and interactions have been omitted. The best that can be achieved 
currently, to improve human surrogates, is to match our simplified understanding of organic tissue behaviour.

Previous studies which have examined human limb impact response have typically either examined the lower leg (Ankrah \& Mills, 2003; Ankrah \& Mills, 2004; Francisco et al., 2000), with particular regards to tibia impacts or considered high strain rate ballistic impacts (Bergeron et al., 2006). Hrysomallis (2009) reported a study of impact response of a human thigh segment (Hrysomallis, 2009), in which both human volunteers and cadavers were tested but further directly comparable data is scarce.

\subsection{External Relevance of Work}

An important application of such work is to relate the mechanical phenomena experienced by the surrogates to some measure of the likelihood of obtaining injuries. Information regarding the exact mechanical loading conditions or thresholds required to illicit particular injuries is vitally important. In sports, contusion injuries are often considered as the highest risk impact injury due to their frequency of occurrence (Crisco et al., 1994; Khattak et al., 2010; Smith et al., 2008), whilst fractures and lacerations are also pertinent considerations.

Contusions are widely considered to be caused by blunt non-penetrating trauma (Crisco et al., 1996) and resulting compression of soft tissues against the bone (Walton \& Rothwell, 1983). Due to ethical constraints, however, little is known about in vivo organic tissue response to impact and the pathophysiological sequalae succeeding it. Previous studies have typically utilised mechanical drop test procedures on the hind limbs of anaesthetised rodents and have investigated regenerative aids to reduce the long term severity of resulting injuries. Few studies have investigated the mechanical causation for contusions (Crisco et al. 1994; Crisco et al., 1996; Sherman et al. 2007; McBrier et al., 2009; Desmoulin \& Anderson, 2011), with only a single study studying the onset in humans (Desmoulin \& Anderson, 2011).

Existing studies lack comparable control over their inputs in terms of masses and drop heights used and are therefore difficult to compare or correlate meaningfully. In terms of physical measures to quantify the onset of contusions, whilst excessive strain is considered to be the injury mechanism, there is little consensus on which indirect mechanical phenomenon value (e.g. force, pressure) to consider (Benier \& Jokl, 2001). Ankrah \& Mills (2004) suggested a value of $1 \mathrm{MPa}$ could be considered as a metric to represent the onset of contusions, however a recent study by Desmoulin \& Anderson (2011) showed a human participant experienced far greater pressures (up to 4.52MPa) without a visible bruise. One of the main issues with such approaches are that there are no common measures for evaluating the effects of the impacts; Desmoulin \& Anderson, qualitatively assessed the size and colour of bruises, though this is suggested to be very site dependent and can vary based on the capillary densities. Other approaches have used MRI to identify specific tissue damage (McBrier et al., 2009), though the distinction between severities of contusions are similarly not well defined.

Studies to further identify the mechanical factors causing injury would be greatly influential and informative in this research but without surrogates or models that produce biofidelic 
stress or strain responses this is difficult. Arguably, the ability of manufacturers to accurately predict or assess the performance of PPE design with respect to injury phenomenon is also similarly restricted without better simulants, surrogates and models. Superior surrogates at least provide PPE designers with a more accurate means to empirically access the relative merits of different designs in anticipation of greater future certainty as to which mechanical response phenomena is most critical.

\subsection{Future Developments}

Further iterations of the PDMS silicones must address methods to overcome the increased stiffness of the adipose simulant at higher strain rates and reduced stiffness of skin tissue under quasi-static loading conditions. The differences in rate dependencies between the silicones and organic tissues suggest that it may be beneficial to develop bespoke blends of silicone to match specific strain rate applications. In addition, the further complexity introduced through consideration of organic tissue anisotropy is a factor which could potentially increase the biofidelity of the developed simulants. The ageing of skin is another pertinent consideration which affects the mechanical properties of the organic tissue (PallierMattei et al., 2014). This could change human mechanical response to impact and injury tolerance levels and represent an area of potential further study.

Further study may also consider the Payne effect, which is a strain softening effect present in filled elastomers at low strain amplitudes in which an energy loss is observed due to fillerfiller interactions. This could potentially affect the manner in which the materials behave under different impact conditions. Due to the high strains associated with sports blunt trauma impacts, this is not expected to be a significant issue; however this effect could be addressed more explicitly in future iterations of the PDMS silicones.

The characterisation of the PDMS simulants under a wider range of strain rates, particularly those pertinent to high rate projectile impacts are also an important area for future research and will enhance confidence in the FE models instead of extrapolating responses from lower rate experiments. This would enable more accurate dynamic FE analyses of the materials as projectile impacts can reach up to $34.6 \mathrm{~ms}^{-1}$ in relevant sports applications (Penrose et al., 1978). Given the high strain rate dependencies of the PDMS simulants and organic tissues, an investigation of surrogate impact behaviour under these higher strain rate conditions is important and could potentially require different PDMS blends for particular strain rate or sports applications.

Although the cylinder geometry used in this study embodied human anthropometric values they still represent large simplifications of actual human morphologies. There exist many levels of increasing geometric complexity and constraint that have not yet been considered. The differences in shape and tissue layer thicknesses in professional athletes are another factor that requires consideration, as well as more biofidelic human constraints.

To generate the computational model several assumptions were required, ranging from the isotropic stress-strain behaviour of the tissues under varying strain rates imposed to the level of adhesion between tissue structures. The puck surrogates were validated against 
experimental data, to establish confidence in the cylindrical thigh model response predictions. A similar validation and optimisation study could be conducted to further validate this model.

The parallel development of synthetic and computational human surrogates will provide further validation and confidence in each approach. The continued development of these technologies provides scope for more biofidelic improved surrogate models.

\section{Conclusions}

This study presents a multi-material human tissue surrogate development approach using additive cure PDMS soft tissues. Target organic tissue properties were established from previous uniaxial compressive tests on skin and adipose tissues and used as a guideline to develop synthetic additive cure PDMS simulants, which were tested through a range of strain rates. Constitutive models were established describing the hyperelastic and viscoelastic behaviour of the simulants which were used in FE models and validated using experimental data from associated drop tests. The FE responses were compared to organic tissue properties and previously used simulants. The new PDMS simulants provided a superior approximation of the predicted organic tissue response than previously used single material soft tissue synthetic simulants.

\section{References}

ALBRIGHT, A.L. and STERN, J.S., 1998. Adipose tissue. In: T.D. FAHEY, ed, Encyclopedia of Sports Medicine and Science. Internet Society for Sport Science, .

ALKHOULI, N., MANSFIELD, J., GREEN, E., BELL, J., KNIGHT, B., LIVERSEDGE, N., THAM, J.C., WELBOURN, R., SHORE, A.C., KOS, K. and WINLOVE, C.P., 2013. The mechanical properties of human adipose tissues and their relationships to the structure and composition of the extracellular matrix. American journal of physiology.Endocrinology and metabolism, 305(12), pp. E1427-35, DOI:10.1152/ajpendo.00111.2013; 10.1152/ajpendo.00111.2013.

ANKERSEN, J., BIRKBECK, A., THOMSON, R. and VANEZIS, P., 1999. Puncture resistance and tensile strength of skin simulants. Proceedings of the Institution of Mechanical Engineers, Part H: Journal of Engineering in Medicine, 213(6), pp. 493-501, DOI:10.1243/0954411991535103.

ANKRAH, S. and MILLS, N., 2003. Performance of football shin guards for direct stud impacts. Sports Engineering, 6(4), pp. 207-219, DOI:10.1007/BF02844024.

ANKRAH, S. and MILLS, N., 2004. Analysis of ankle protection in Association football. Sports Engineering, 7(1), pp. 41-52, DOI:10.1007/BF02843972.

AVON, S. and WOOD, R., 2005. Porcine skin as an in vivo model for ageing of human bite marks. J Forensic Odontostomatol, 23(2), pp. 30-39.

AZAR, F.S., METAXAS, D.N. and SCHNALL, M.D., 2002. Methods for modeling and predicting mechanical deformations of the breast under external perturbations. Medical image analysis, 6(1), pp. 1-27, DOI:10.1016/S1361-8415(01)00053-6.

BEINER, J.M. and JOKL, P., 2001. Muscle contusion injuries: current treatment options. The Journal of the American Academy of Orthopaedic Surgeons, 9(4), pp. 227-237.

BERGERON, D.M., ANDERSON, I.B., COLEY, C.G. and FALL, R.W., 2006. Assessment of Lower Leg Injury from Land Mine Blast Phase 1: Test Results using a Frangible Surrogate Leg with Assorted Protective Footwear and Comparison with Cadaver Test Data. DRDC Suffield TR 2006-051. Valcartier, Canada: Defence Research and Development Canada.

BROWN, I.A., 1973. A scanning electron microscope study of the effects of uniaxial tension on human skin. British Journal of Dermatology, 89(4), pp. 383-393, DOI:10.1111/j.1365-2133.1973.tb02993.x.

COHEN, R., HOOLEY, C. and MCCRUM, N., 1976. Viscoelastic creep of collagenous tissue. Journal of Biomechanics, 9(4), pp. 175-184, DOI:10.1016/0021-9290(76)90002-6.

COMLEY, K. and FLECK, N., 2012. The compressive response of porcine adipose tissue from low to high strain rate. International Journal of Impact Engineering, 46, pp. 1-10, DOI:10.1016/j.ijimpeng.2011.12.009.

COMLEY, K. and FLECK, N.A., 2010. A micromechanical model for the Young's modulus of adipose tissue. International Journal of Solids and Structures, 47(21), pp. 2982-2990, DOI:10.1016/j.ijsolstr.2010.07.001. 
CRISCO, J., HENTEL, K., JACKSON, W., GOEHNER, K. and JOKL, P., 1996. Maximal contraction lessens impact response in a muscle contusion model. Journal of Biomechanics, 29(10), pp. 1291-1296, DOI:10.1016/0021-9290(96)00047-4.

CRISCO, J.J., JOKL, P., HEINEN, G.T., CONNELL, M.D. and PANJABI, M.M., 1994. A muscle contusion injury model. Biomechanics, physiology, and histology. The American Journal of Sports Medicine, 22(5), pp. 702-710, DOI:10.1177/036354659402200521.

DESMOULIN, G.T. and ANDERSON, G.S., 2011. Method to Investigate Contusion Mechanics in Living Humans. Journal of Forensic Biomechanics, 2(1), pp. 1-10.

DOUGLAS, W.R., 1972. Of pigs and men and research: a review of applications and analogies of the pig, sus scrofa, in human medical research. Space life sciences, 3(3), pp. 226-234, DOI:10.1007/BF00928167.

DUNN, M.G., SILVER, F.H. and SWANN, D.A., 1985. Mechanical analysis of hypertrophic scar tissue: structural basis for apparent increased rigidity. Journal of investigative dermatology, 84(1), pp. 9-13, DOI:10.1111/1523-1747.ep12274528.

EDWARDS, C. and MARKS, R., 1995. Evaluation of biomechanical properties of human skin. Clinics in dermatology, 13(4), pp. 375-380, DOI:10.1016/0738-081X(95)00078-T.

EGELBREKTSSON, K., 2011. Evaluation of material models in LS-DYNA for impact simulation of white adipose tissue, Chalmers University of Technology.

ERDEMIR, A., VIVEIROS, M.L., ULBRECHT, J.S. and CAVANAGH, P.R., 2006. An inverse finite-element model of heel-pad indentation. Journal of Biomechanics, 39(7), pp. 1279-1286, DOI:10.1016/j.jbiomech.2005.03.007.

FACKLER, M.L., 1988. Ordnance gelatin for ballistic studies: Detrimental effect of excess heat used in gelatin preparation. American Journal of Forensic Medicine \& Pathology, 9(3), pp. 218-219, DOI:10.1097/00000433-198809000-00008.

FARVID, M., NG, T., CHAN, D., BARRETT, P. and WATTS, G., 2005. Association of adiponectin and resistin with adipose tissue compartments, insulin resistance and dyslipidaemia. Diabetes, Obesity and Metabolism, 7(4), pp. 406-413, DOI:10.1111/j.14631326.2004.00410.x.

FIDANZA, F., KEYS, A. and ANDERSON, J.T., 1953. Density of body fat in man and other mammals. Journal of applied physiology, 6(4), pp. 252-256.

FINLAY, J.B., 1978. Thixotropy in human skin. Journal of Biomechanics, 11(6), pp. 333-342, DOI:10.1016/0021-9290(78)90066-0.

FLYNN, C. and MCCORMACK, B.A., 2008. Finite element modelling of forearm skin wrinkling. Skin research and technology, 14(3), pp. 261-269, DOI:10.1111/j.1600-0846.2008.00289.x.

FONTANELLA, C., MATTEOLI, S., CARNIEL, E., WILHJELM, J.E., VIRGA, A., CORVI, A. and NATALI, A., 2012. Investigation on the load-displacement curves of a human healthy heel pad: In vivo compression data compared to numerical results. Medical engineering \& physics, 34(9), pp. 1253-1259, DOI:10.1016/j.medengphy.2011.12.013.

FRANCISCO, A.C., NIGHTINGALE, R.W., GUILAK, F., GLISSON, R.R. and GARRETT JR, W.E., 2000. Comparison of soccer shin guards in preventing tibia fracture. The American Journal of Sports Medicine, 28(2), pp. 227-233.

GALLAGHER, A., NÍ ANNAIDH, A. and BRUYÈRE, K., 2012. Dynamic tensile properties of human skin, 2012 International Research Council on the Biomechanics of Injury, 12 - 14 September 2012 2012, International Research Council on the Biomechanics of Injury, pp. 494-502.

GEERLIGS, M., PETERS, G.W., ACKERMANS, P.A., OOMENS, C.W. and BAAIJENS, F.P., 2008. Linear viscoelastic behavior of subcutaneous adipose tissue. Biorheology, 45(6), pp. 677-688, DOI:10.3233/BIR-2008-0517.

GEFEN, A. and HABERMAN, E., 2007. Viscoelastic properties of ovine adipose tissue covering the gluteus muscles. Journal of Biomechanical Engineering, 129(6), pp. 924-930, DOI:10.1115/1.2800830.

GOLDSMITH, L.A., 1990. My organ is bigger than your organ. Archives of Dermatology, 126(3), pp. 301-302, DOI:10.1001/archderm.1990.01670270033005.

HALKON, B.J., MITCHELL, S.R., PAYNE, T. and CARBO, J., 2014. The biomechanics of human impacts in basketball. Procedia Engineering, 72, pp. 214-219, DOI:10.1016/j.proeng.2014.06.038.

HAUT, R., 1989. The effects of orientation and location on the strength of dorsal rat skin in high and low speed tensile failure experiments. Journal of Biomechanical Engineering, 111(2), pp. 136-140, DOI:10.1115/1.3168354.

HOLZAPFEL, G.A., 2004. Computational biomechanics of soft biological tissue. Encylclopedia of Computational Mechanics. Graz, Austria: Wiley Online Library, .

HRYSOMALLIS, C., 2009. Surrogate thigh model for assessing impact force attenuation of protective pads. Journal of Science and Medicine in Sport, 12(1), pp. 35-41, DOI:10.1016/j.jsams.2007.07.013.

JAMISON, C., MARANGONI, R. and GLASER, A., 1968. Viscoelastic properties of soft tissue by discrete model characterization. Journal of Biomechanics, 1(1), pp. 33-46, DOI:10.1016/0021-9290(68)90036-5.

JANSEN, L. and ROTTIER, P., 1958. Comparison of the mechanical properties of strips of human abdominal skin excised from below and from above the umbilic. Dermatologica, 117(4), pp. 252-258, DOI:10.1159/000255597.

JEE, T. and KOMVOPOULOS, K., 2014. Skin viscoelasticity studied in vitro by microprobe-based techniques. Journal of Biomechanics, 47(2), pp. 553-559, DOI:10.1016/j.jbiomech.2013.10.006 
JUSSILA, J., 2004. Preparing ballistic gelatine-review and proposal for a standard method. Forensic science international, 141(2), pp. 9198, DOI:10.1016/j.forsciint.2003.11.036.

KHATTAK, M.J., AHMAD, T., REHMAN, R., UMER, M., HASAN, S.H. and AHMED, M., 2010. Muscle healing and nerve regeneration in a muscle contusion model in the rat. The Journal of bone and joint surgery. British volume, 92(6), pp. 894-899, DOI:10.1302/0301620X.92B6.22819.

KROUSKOP, T.A., WHEELER, T.M., KALLEL, F., GARRA, B.S. and HALL, T., 1998. Elastic moduli of breast and prostate tissues under compression. Ultrasonic imaging, 20(4), pp. 260-274, DOI:10.1177/016173469802000403.

LANIR, Y. and FUNG, Y., 1974. Two-dimensional mechanical properties of rabbit skin-I. Experimental system. Journal of Biomechanics, 7(1), pp. 29-34, DOI:10.1016/0021-9290(74)90067-0.

LIM, J., HONG, J., CHEN, W.W. and WEERASOORIYA, T., 2011. Mechanical response of pig skin under dynamic tensile loading. International Journal of Impact Engineering, 38(2), pp. 130-135, DOI:10.1016/j.ijimpeng.2010.09.003.

LIU, Z. and YEUNG, K., 2008. The preconditioning and stress relaxation of skin tissue. Journal of Biomedical \& Pharmaceutical Engineering, 2(1), pp. 22-28.

MCBRIER, N.M., NEUBERGER, T., OKITA, N., WEBB, A. and SHARKEY, N., 2009. Reliability and validity of a novel muscle contusion device. Journal of athletic training, 44(3), pp. 275-278, DOI:10.4085/1062-6050-44.3.275.

MCELHANEY, J.H., 1966. Dynamic response of bone and muscle tissue. Journal of applied physiology, 21(4), pp. 1231-1236.

MENDEZ, J. and KEYS, A., 1960. Density and composition of mammalian muscle. Metabolism, 9(2), pp. 184-188.

MILLER-YOUNG, J.E., DUNCAN, N.A. and BAROUD, G., 2002. Material properties of the human calcaneal fat pad in compression: experiment and theory. Journal of Biomechanics, 35(12), pp. 1523-1531, DOI:10.1016/S0021-9290(02)00090-8.

NATALI, A., FONTANELLA, C. and CARNIEL, E., 2012. A numerical model for investigating the mechanics of calcaneal fat pad region. Journal of the mechanical behavior of biomedical materials, 5(1), pp. 216-223, DOI:10.1016/j.jmbbm.2011.08.025.

NÍ ANNAIDH, A., BRUYÈRE, K., DESTRADE, M., GILCHRIST, M.D. and OTTÉNIO, M., 2012. Characterization of the anisotropic mechanical properties of excised human skin. Journal of the Mechanical Behavior of Biomedical Materials, 5(1), pp. 139-148, DOI:10.1016/j.jmbbm.2011.08.016.

PAILLER-MATTEI, C., BEC, S. and ZAHOUANI, H., 2008. In vivo measurements of the elastic mechanical properties of human skin by indentation tests. Medical engineering \& physics, 30(5), pp. 599-606, DOI:10.1016/j.medengphy.2007.06.011.

PAILLER-MATTEI, C., LAQUIÈZE, L., DEBRET, R., TUPIN, S., AIMOND, G., SOMMER, P. and ZAHOUANI, H., 2014. Rheological behaviour of reconstructed skin. Journal of the Mechanical Behavior of Biomedical Materials, 37, pp. 251-263, DOI:10.1016/j.jmbbm.2014.05.030

PAUS, R., KLEIN, J., PERMANA, P., OWECKI, M., CHALDAKOV, G., BÖHM, M., HAUSMAN, G., LAPIÈRE, C., ATANASSOVA, P. and SOWIŃSKI, J., 2007. What are subcutaneous adipocytes really good for...? Experimental dermatology, 16(1), pp. 45-47, DOI:10.1111/j.1600-0625.2006.00519_1.x.

PAYNE, T., MITCHELL, S.R., BIBB, R. and WATERS, M., 2014. Development of Novel Synthetic Muscle Tissues for Sports Impact Surrogates. Journal of the Mechanical Behavior of Biomedical Materials,

PAYNE, T., MITCHELL, S. and BIBB, R., 2013. Design of human surrogates for the study of biomechanical injury: a review. Critical Reviews $^{\mathrm{TM}}$ in Biomedical Engineering, 41(1), pp. 51-89, DOI:10.1615/CritRevBiomedEng.2013006847.

PENROSE, T., FOSTER, D. and BLANKSBY, B., 1976. Release velocities of fast bowlers during a cricket test match. Australian Journal for Health, Physical Education and Recreation, 71(Supplement to Australian Journal for Health, Physical Recreation \& Education), pp. 2-5.

PODNOS, E., BECKER, E., KLAWITTER, J. and STRZEPA, P., 2006. FEA analysis of silicone MCP implant. Journal of Biomechanics, 39(7), pp. 1217-1226, DOI:10.1016/j.jbiomech.2005.03.019.

POTTS, R.O., BURAS JR, E.M. and CHRISMAN JR, D.A., 1984. Changes with age in the moisture content of human skin. Journal of investigative dermatology, 82(1), pp. 97-100, DOI:10.1111/1523-1747.ep12259203.

RHO, J.Y., ASHMAN, R.B. and TURNER, C.H., 1993. Young's modulus of trabecular and cortical bone material: ultrasonic and microtensile measurements. Journal of Biomechanics, 26(2), pp. 111-119, DOI:10.1016/0021-9290(93)90042-D.

ROBBINS, S.E., GOUW, G.J. and HANNA, A.M., 1989. Running-related injury prevention through innate impact-moderating behavior. Medicine and science in sports and exercise, 21(2), pp. 130-139.

ROHAN, C., BADEL, P., LUN, B., RASTEL, D. and AVRIL, S., 2013. Biomechanical response of varicose veins to elastic compression: A numerical study. Journal of Biomechanics, 46(3), pp. 599-603, DOI:10.1016/j.jbiomech.2012.10.043.

SAMANI, A. and PLEWES, D., 2004. A method to measure the hyperelastic parameters of ex vivo breast tissue samples. Physics in Medicine and Biology, 49(18), pp. 4395-4405, DOI:10.1088/0031-9155/49/18/014

SAMANI, A., ZUBOVITS, J. and PLEWES, D., 2007. Elastic moduli of normal and pathological human breast tissues: an inversiontechnique-based investigation of 169 samples. Physics in Medicine and Biology, 52(6), pp. 1565-1576, DOI:10.1088/0031-9155/52/6/002.

SAMANI, A., BISHOP, J., LUGINBUHL, C. and PLEWES, D.B., 2003. Measuring the elastic modulus of ex vivo small tissue samples. Physics in Medicine and Biology, 48(14), pp. 2183-2198, DOI:10.1088/0031-9155/48/14/310. 
SAPOZHNIKOV, S. and IGNATOVA, A., 2013. Experimental and theoretical investigation of deformation and fracture of subcutaneous fat under compression. Mechanics of Composite Materials, 48(6), pp. 649-654, DOI:10.1007/s11029-013-9309-7.

SARVAZYAN, A.P., GOUKASSIAN, D., MAEVSKY, E. and ORANSKARA, G., 1994. Elasticity imaging as a new modality of medical imaging for cancer detection, Proc of International Workshop "Interaction of Ultrasound with Biological Media" 1994, Valenciennes, France, pp. 69-81.

SARVAZYAN, A.P., RUDENKO, O.V., SWANSON, S.D., FOWLKES, J.B. and EMELIANOV, S.Y., 1998. Shear wave elasticity imaging: a new ultrasonic technology of medical diagnostics. Ultrasound in medicine \& biology, 24(9), pp. 1419-1435, DOI:0.1016/S03015629(98)00110-0.

SCHMOOK, F.P., MEINGASSNER, J.G. and BILLICH, A., 2001. Comparison of human skin or epidermis models with human and animal skin in in-vitro percutaneous absorption. International journal of pharmaceutics, 215(1), pp. 51-56, DOI:10.1016/S0378-5173(00)00665-7.

SELLIER, K.G. and KNEUBUEHL, B.P., 1994. Wound ballistics and the scientific background. New York: Elsevier Science Health Science div.

SHERGOLD, O.A., FLECK, N.A. and RADFORD, D., 2006. The uniaxial stress versus strain response of pig skin and silicone rubber at low and high strain rates. International Journal of Impact Engineering, 32(9), pp. 1384-1402, DOI:10.1016/j.ijimpeng.2004.11.010.

SHERMAN, D., BIR, C., VIANO, D. and HAACKE, E.M., 2007. Evaluation and Quantification of Bruising, International Society of Biomechanics XXth Congress - ASB 29th Annual Meeting, July 31 - August 5 2007, Cleeveland, Ohio, pp. 700.

SIMS, A., STAIT-GARDNER, T., FONG, L., MORLEY, J., PRICE, W., HOFFMAN, M., SIMMONS, A. and SCHINDHELM, K., 2010. Elastic and viscoelastic properties of porcine subdermal fat using MRI and inverse FEA. Biomechanics and modeling in mechanobiology, 9(6), pp. 703-711, DOI:10.1007/s10237-010-0207-9.

SMITH, C., KRUGER, M.J., SMITH, R.M. and MYBURGH, K.H., 2008. The inflammatory response to skeletal muscle injury. Sports medicine, 38(11), pp. 947-969, DOI:10.2165/00007256-200838110-00005.

SOMMER, G., EDER, M., KOVACS, L., PATHAK, H., BONITZ, L., MUELLER, C., REGITNIG, P. and HOLZAPFEL, G.A., 2013. Multiaxial mechanical properties and constitutive modeling of human adipose tissue: A basis for preoperative simulations in plastic and reconstructive surgery. Acta biomaterialia, 9(11), pp. 9036-9048, DOI:10.1016/j.actbio.2013.06.011.

SONG, B., CHEN, W., GE, Y. and WEERASOORIYA, T., 2007. Dynamic and quasi-static compressive response of porcine muscle. Journal of Biomechanics, 40(13), pp. 2999-3005, DOI:10.1016/j.jbiomech.2007.02.001.

SUGIHARA, T., OHURA, T., HOMMA, K. and IGAWA, H., 1991. The extensibility in human skin: variation according to age and site. British journal of plastic surgery, 44(6), pp. 418-422, DOI:10.1016/0007-1226(91)90199-T.

TATAR, Y., RAMAZANOGLU, N., CAMLIGUNEY, A.F., SAYGI, E.K. and COTUK, H.B., 2014. The Effectiveness of Shin Guards Used by Football Players. Journal of Sports Science and Medicine, 13(1), pp. 120-127.

TIOSSI, R., VASCO, M.A., LIN, L., CONRAD, H.J., BEZZON, O.L., RIBEIRO, R.F. and FOK, A.S., 2013. Validation of finite element models for strain analysis of implant-supported prostheses using digital image correlation. Dental Materials, 29(7), pp. 788-796, DOI:10.1016/j.dental.2013.04.010.

VAN HOUTEN, E.E.W., DOYLEY, M.M., KENNEDY, F.E., WEAVER, J.B. and PAULSEN, K.D., 2003. Initial in vivo experience with steady-state subzone-based MR elastography of the human breast. Journal of Magnetic Resonance Imaging, 17(1), pp. 72-85, DOI:10.1002/jmri.10232.

VAN LOOCKE, M., SIMMS, C. and LYONS, C., 2009. Viscoelastic properties of passive skeletal muscle in compression-Cyclic behaviour. Journal of Biomechanics, 42(8), pp. 1038-1048, DOI:10.1016/j.jbiomech.2009.02.022.

WALTON, M. and ROTHWELL, A.G., 1983. Reactions of thigh tissues of sheep to blunt trauma. Clinical orthopaedics and related research, 176, pp. 273-281, DOI:10.1097/00003086-198306000-00040.

WANG, M., YANG, H., SUN, Z., GUO, L. and OU, X., 2006. Dynamic explicit FE modeling of hot ring rolling process. Transactions of Nonferrous Metals Society of China, 16(6), pp. 1274-1280, DOI:10.1016/S1003-6326(07)60006-5.

WARD, S.R. and LIEBER, R.L., 2005. Density and hydration of fresh and fixed human skeletal muscle. Journal of Biomechanics, 38(11), pp. 2317-2320, DOI:10.1016/j.jbiomech.2004.10.001.

WU, J.Z., CUTLIP, R.G., ANDREW, M.E. and DONG, R.G., 2007. Simultaneous determination of the nonlinear-elastic properties of skin and subcutaneous tissue in unconfined compression tests. Skin Research and Technology, 13(1), pp. 34-42, DOI:10.1111/j.16000846.2007.00182.x.

WU, J.Z., DONG, R.G., SMUTZ, W.P. and SCHOPPER, A.W., 2003. Nonlinear and viscoelastic characteristics of skin under compression: experiment and analysis. Bio-medical materials and engineering, 13(4), pp. 373-385.

YENI, Y., BROWN, C. and NORMAN, T., 1998. Influence of bone composition and apparent density on fracture toughness of the human femur and tibia. Bone, 22(1), pp. 79-84, DOI:10.1016/S8756-3282(97)00227-5.

YOUNG, D.A. and CHRISTMAN, K.L., 2012. Injectable biomaterials for adipose tissue engineering. Biomedical Materials, 7(2), pp. 024104, DOI:10.1088/1748-6041. 


\section{List of Figures}

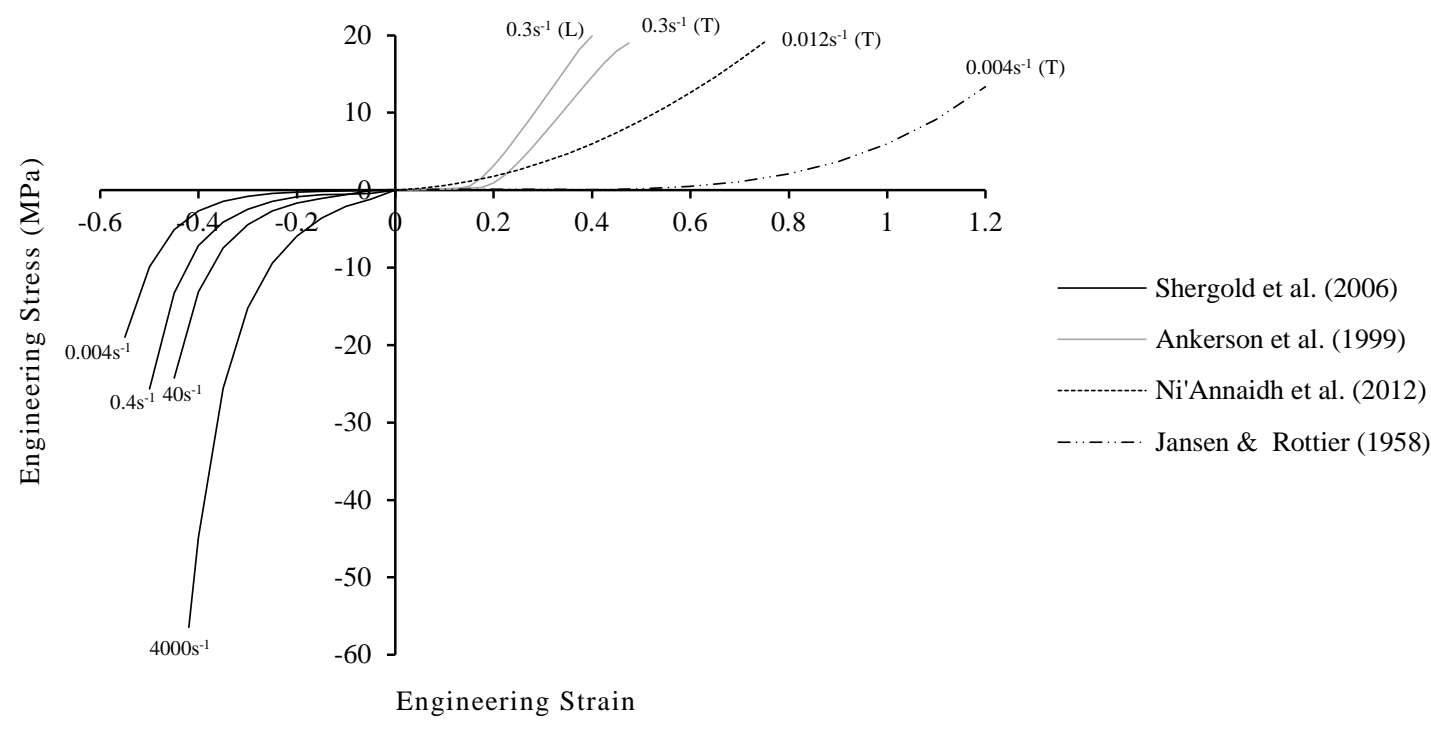

Figure 11 - Engineering stress-strain graphs for a range of organic skin tissue samples at different strain rates ( $\mathrm{T}$ transverse; L - longitudinal)

(a)

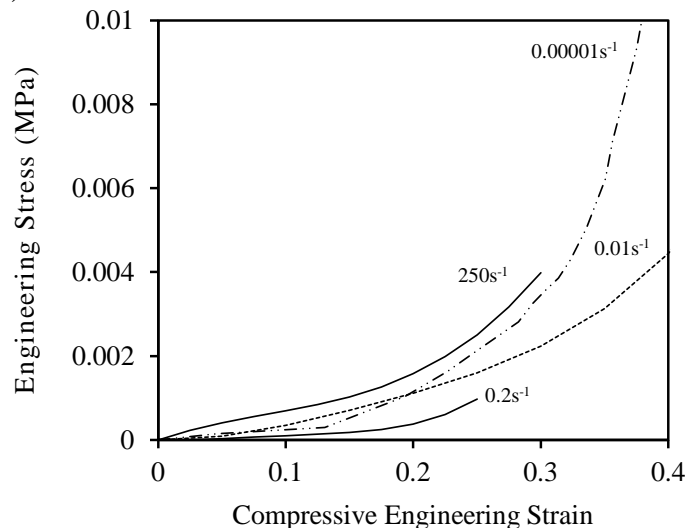

Comley \& Fleck (2012) (b)

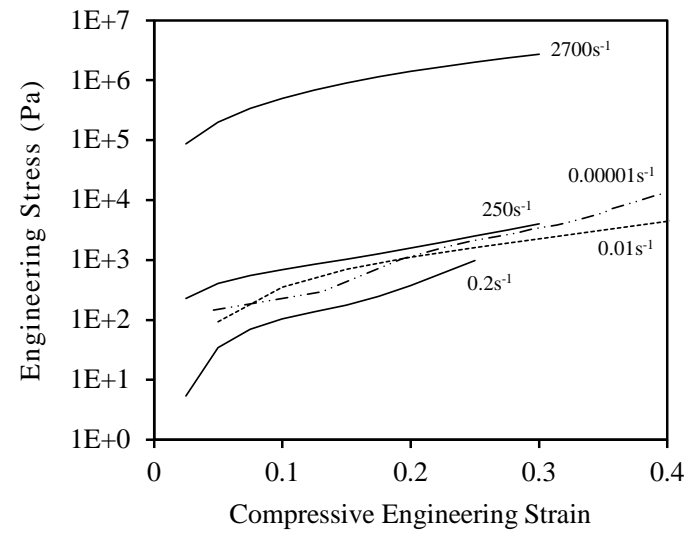

Miller-Young et al. (2002) _ _...... Wu et al. (2007)

Figure 12 - Compressive engineering stress-strain graphs for a range of organic adipose tissue samples at different strain rates in (a) linear and (b) log-linear plots 


\section{Figure 3}

(a)

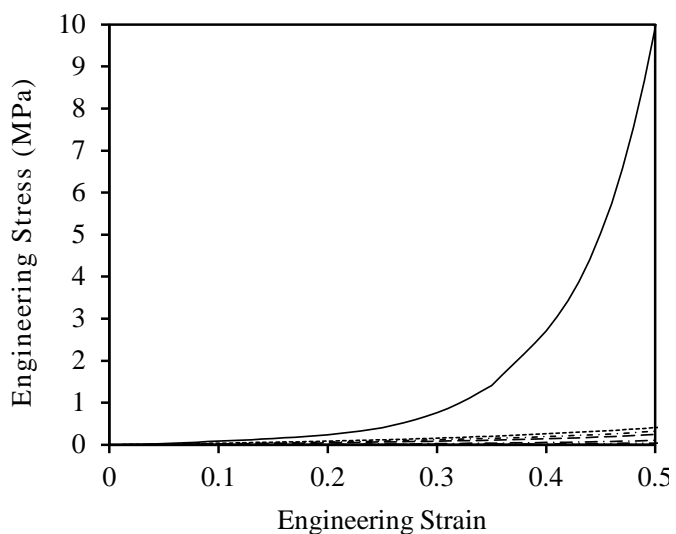

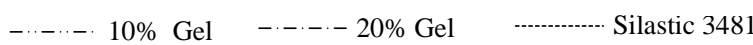

(b)

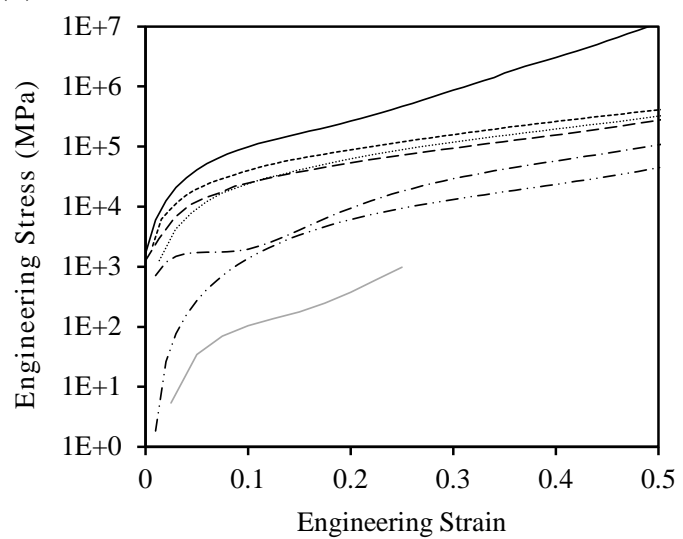

Silastic 3483

----- Silastic 3487

Adipose (Comley \& Fleck, 2012) Skin (Shergold et al., 2006)

Figure 13 - Quasi-static stress-strain graphs showing the uniaxial compressive responses of organic adipose (Comley \& Fleck, 2012) and skin (Shergold et al., 2006) tissues compared to soft tissue simulants in (a) linear and (b) log-linear graphs

\section{Figure 4}

(a)

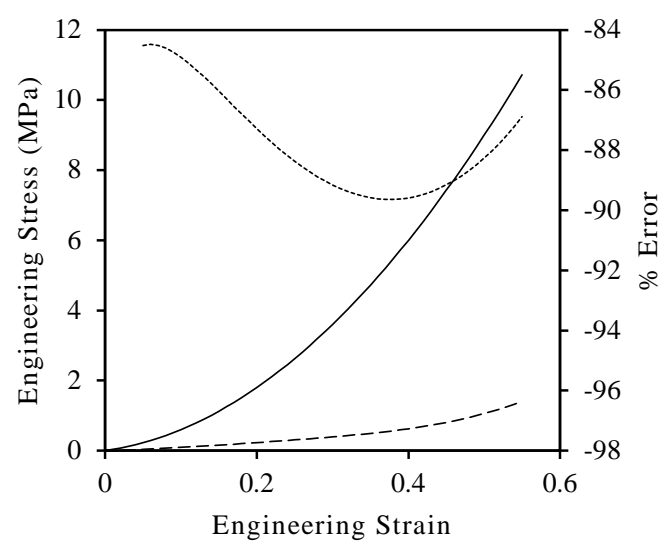

PDMS Skin Simulant (b)

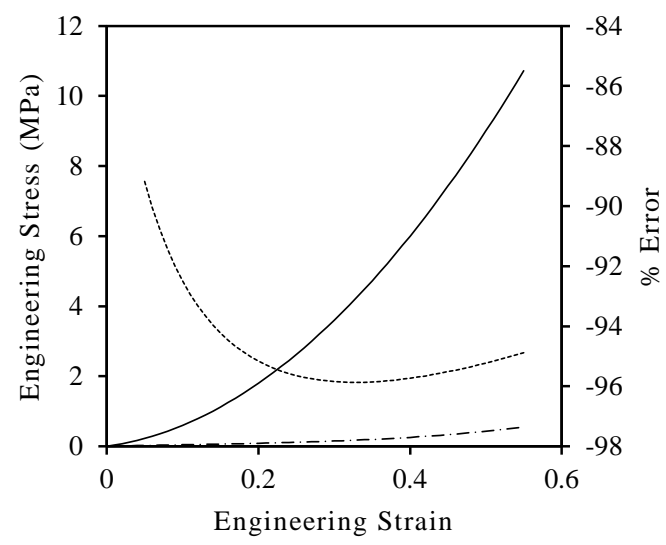

- - - - - Silastic 3481 \% Error

Figure 14 - Quasi-static stress-strain graphs for: (a) PDMS skin simulant compared to organic tissue (Shergold et al., 2006) and (b) Silastic 3481 simulant compared to organic skin tissue (Shergold et al., 2006) 


\section{Figure 5}

(a)

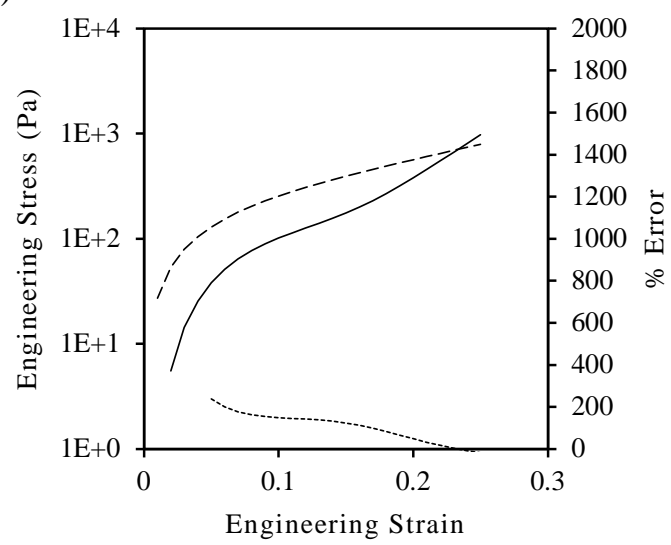

(b)

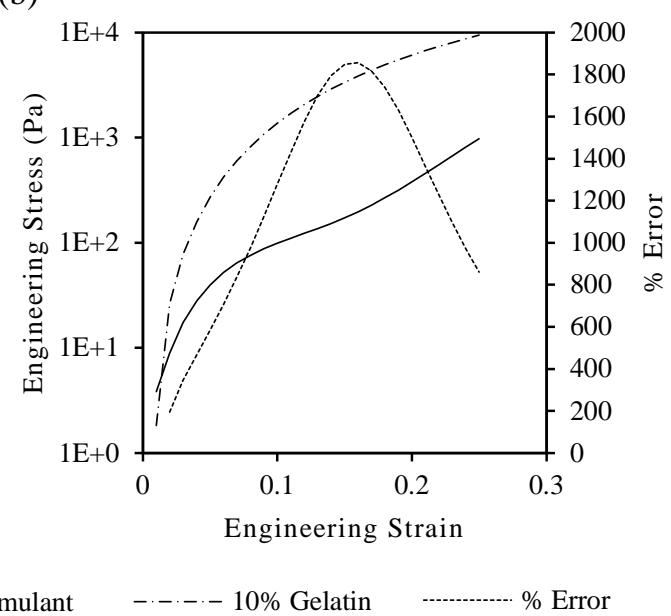

Figure 15 - Log-linear quasi-static stress-strain graphs for: (a) PDMS adipose simulant compared to organic tissue (Comley \& Fleck, 2012) and (b) $10 \%$ gelatin simulant compared to organic adipose tissue (Comley \& Fleck, 2012)

\section{Figure 6}

(a)

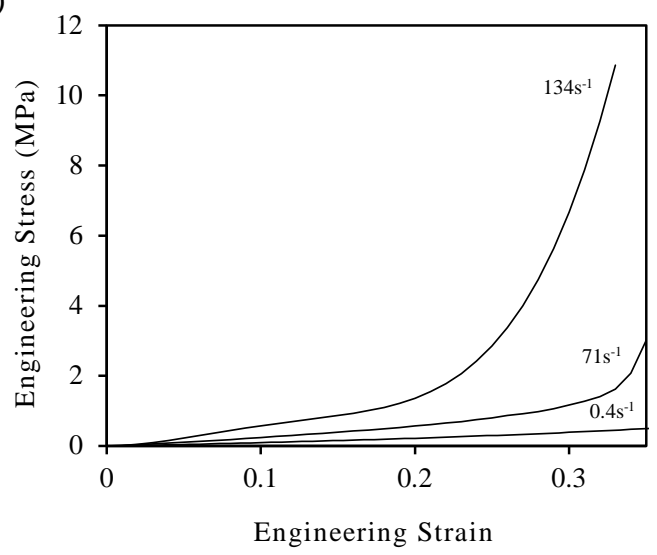

(b)

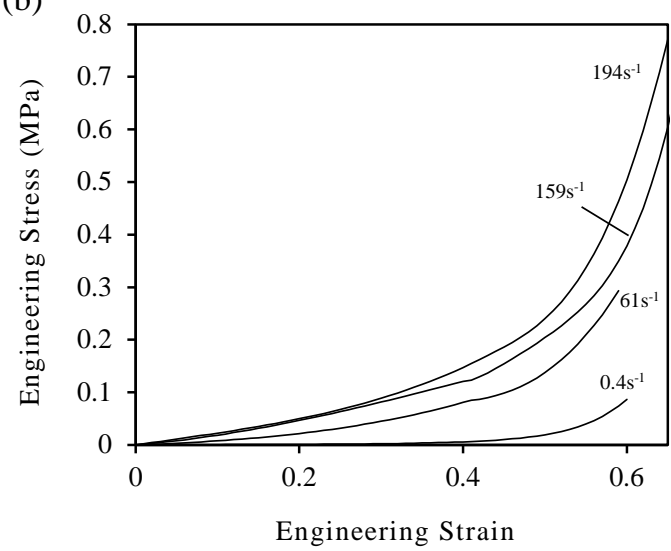

Figure 16 - Intermediate strain rate engineering stress-strain curves for: (a) PDMS skin simulant and (b) PDMS adipose simulants 


\section{Figure 7}

(a)

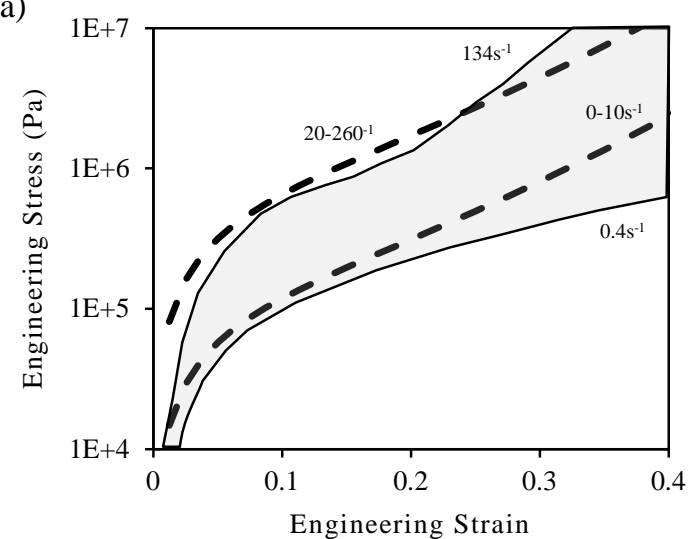

(b)

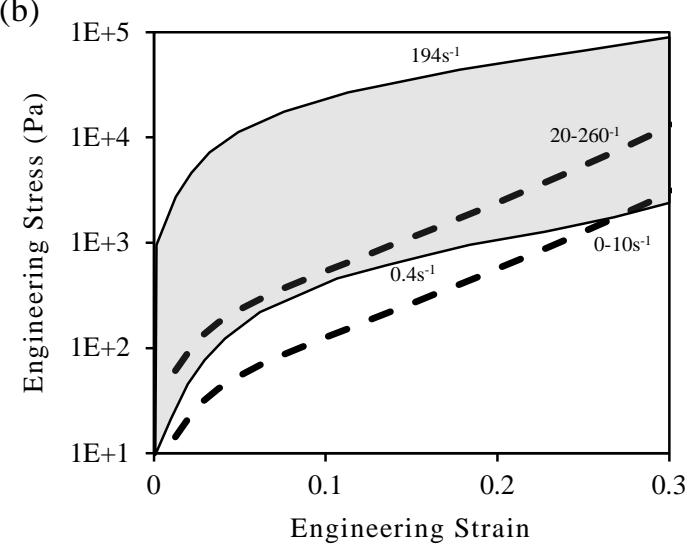

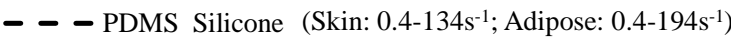

Figure 17 - Log-linear engineering stress-strain graphs showing a comparison between PDMS simulants and organic tissue data at intermediate strain rates for: (a) skin and (b) adipose tissues

\section{$\underline{\text { Figure } 8}$}

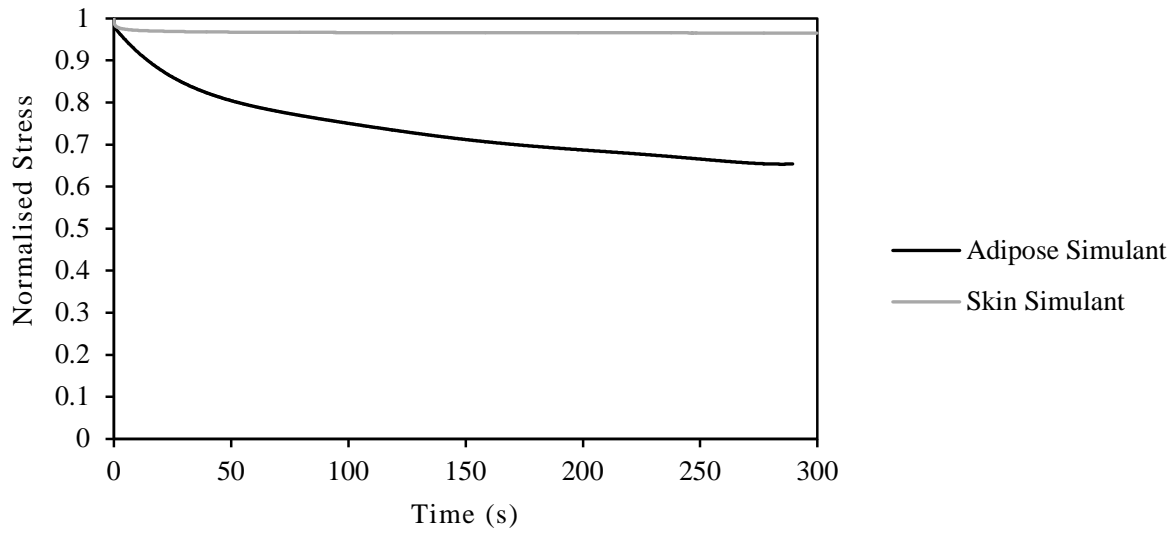

Figure 18 Normalised stress-time plot showing stress relaxation in PDMS skin and adipose tissue simulants 


\section{Figure 9}

(a)

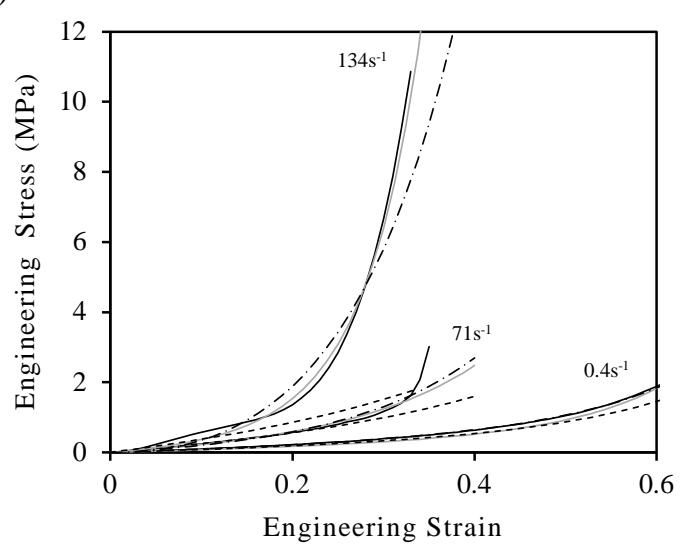

(b)

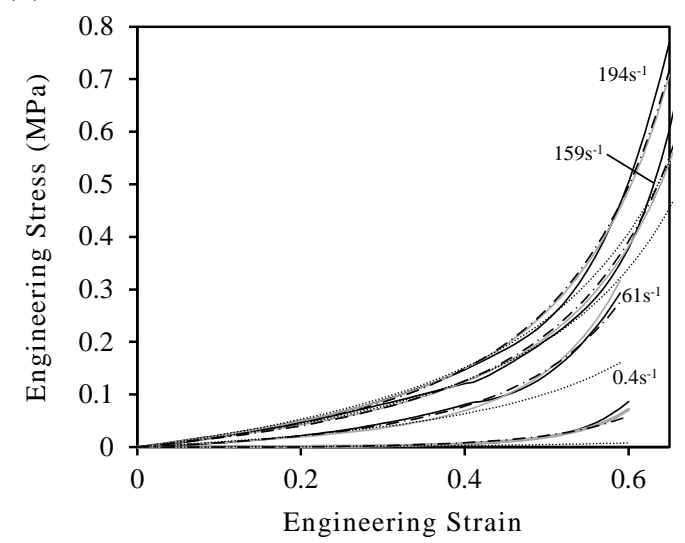

intermediate strain rates

\section{Figure 10}

(a)
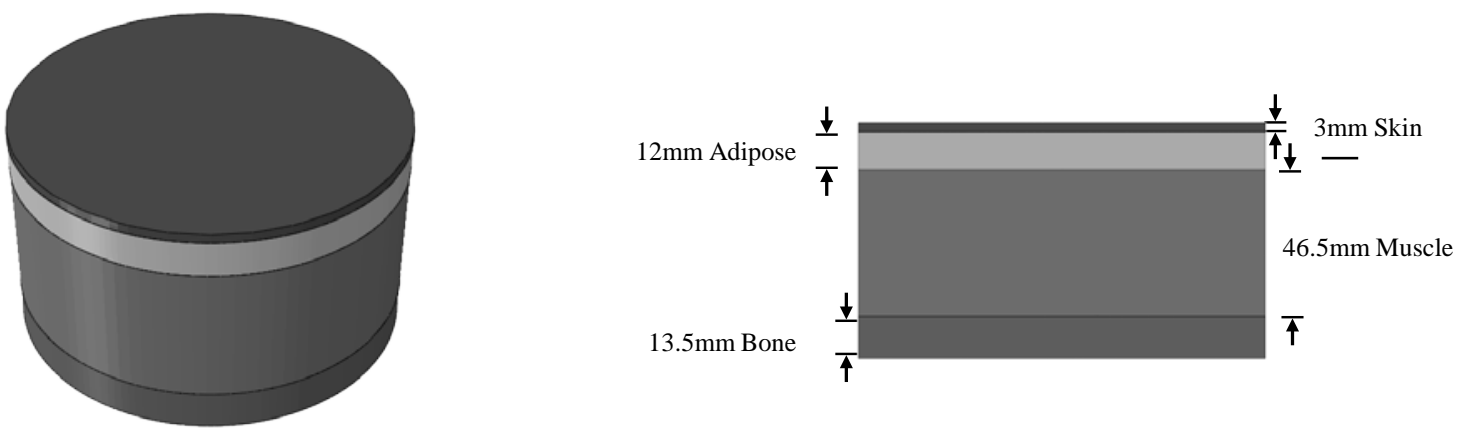

(b)
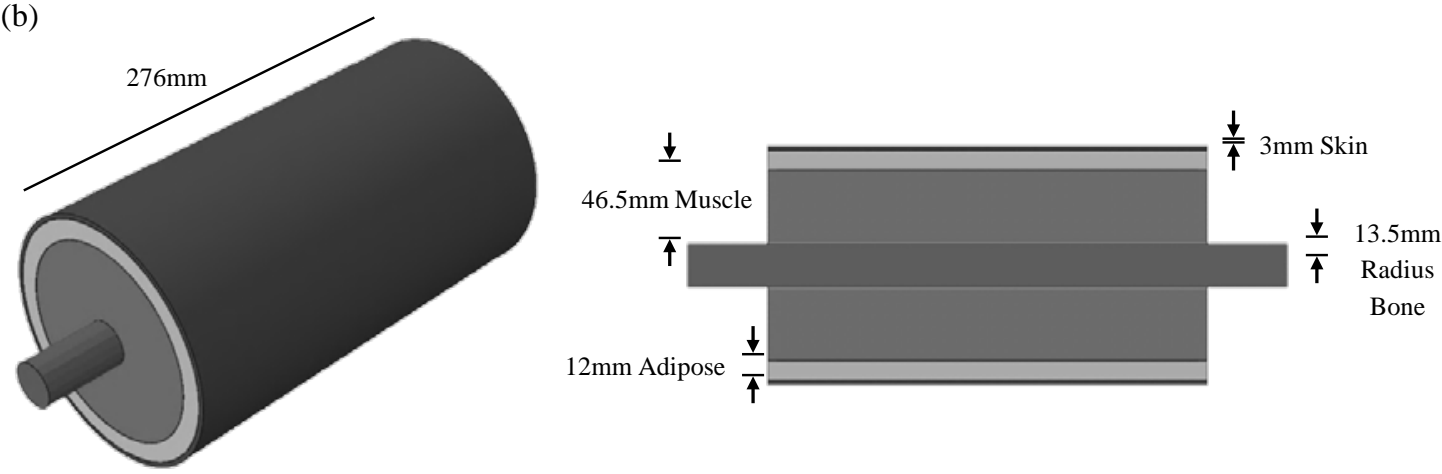

Figure 10 -Surrogate geometric configurations for: (a) layered puck and (b) cylinder models 


\section{Figure 11}

(a)

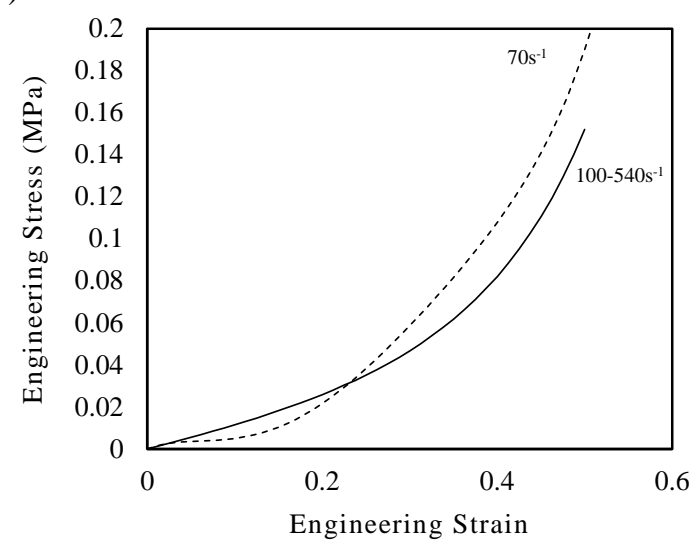

(b)

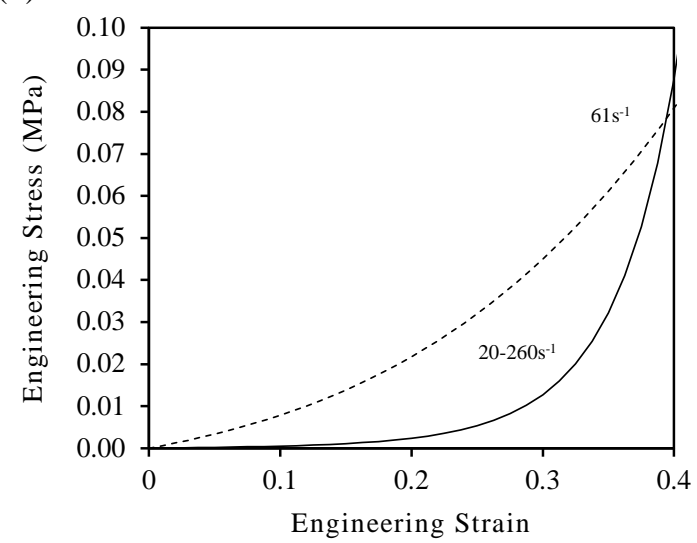

(c)

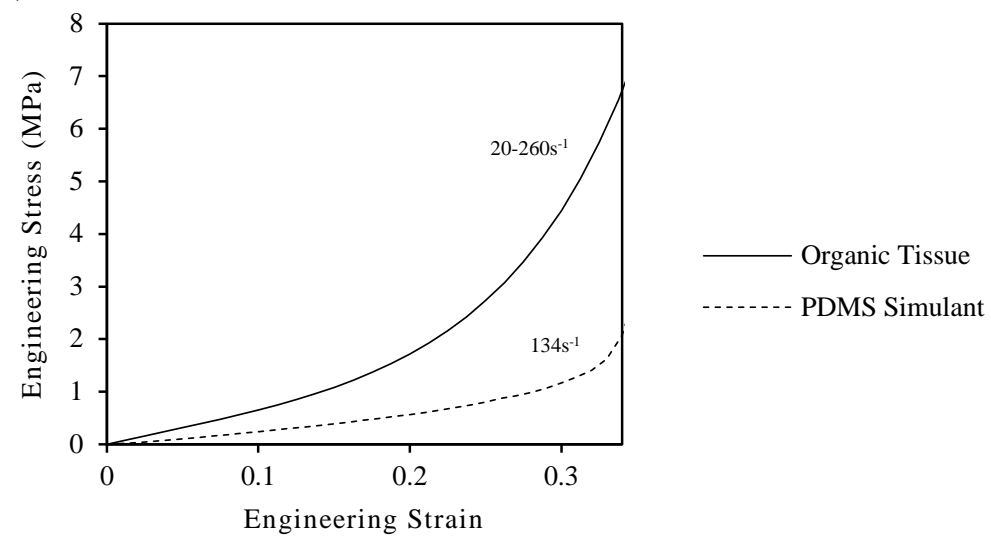

Figure 11 - Engineering stress-strain graphs showing the organic tissue and PDMS simulant data used in FE simulations in: (a) relaxed muscle; (b) subcutaneous tissue; (c) skin

\section{Figure 12}

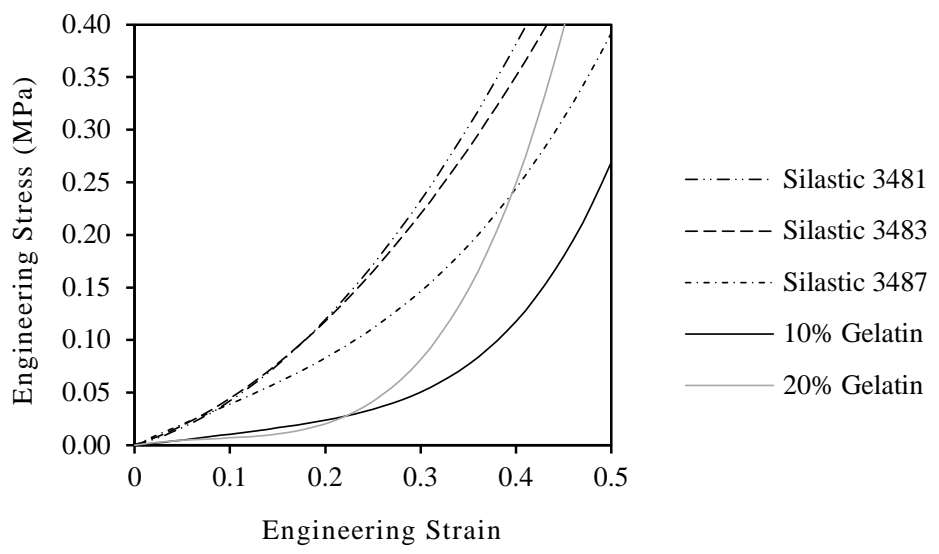

Figure 12 - Compressive engineering stress-strain graphs of Silastic simulants and ballistics gelatin at representative intermediate strain rates 


\section{Figure 13}

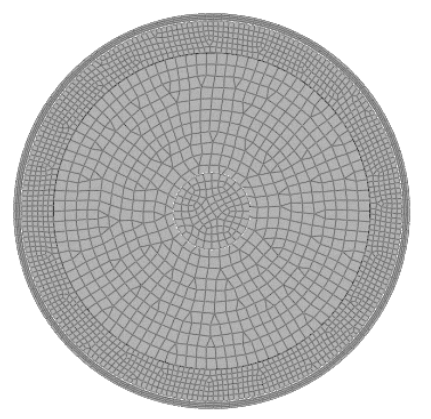

Figure 13 - Cylindrical surrogate mesh density

\section{Figure 14}

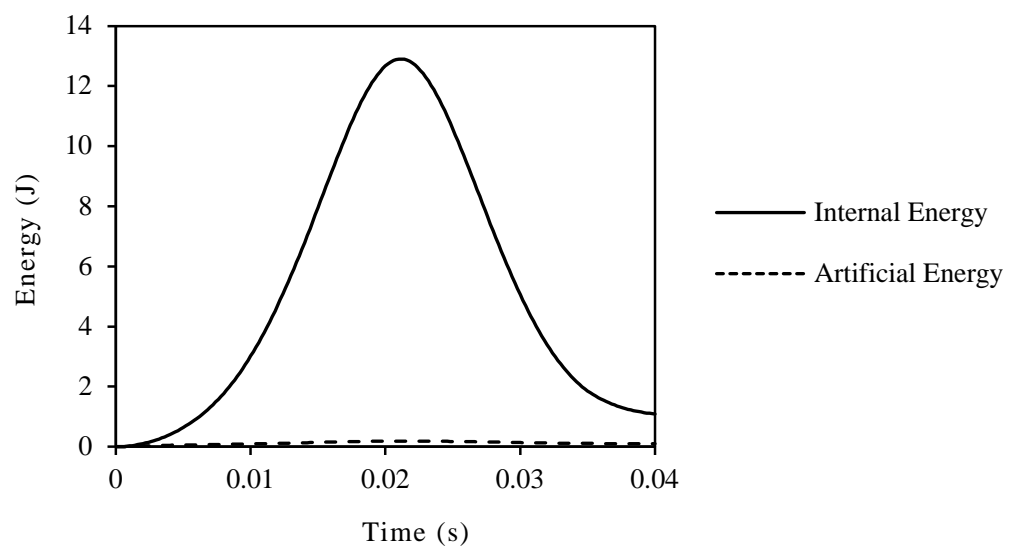

Figure 14 - Artificial energy/internal energy vs. time graphs for knee impact in an organic tissue cylinder surrogate

\section{Figure 15}
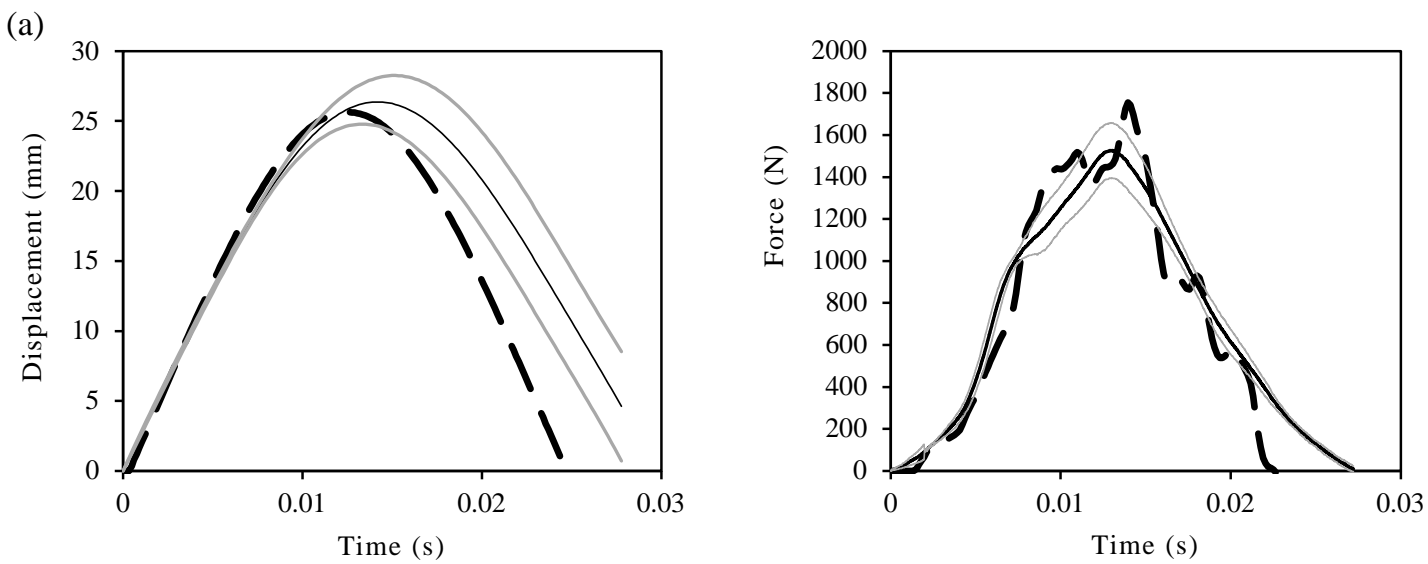
(b)

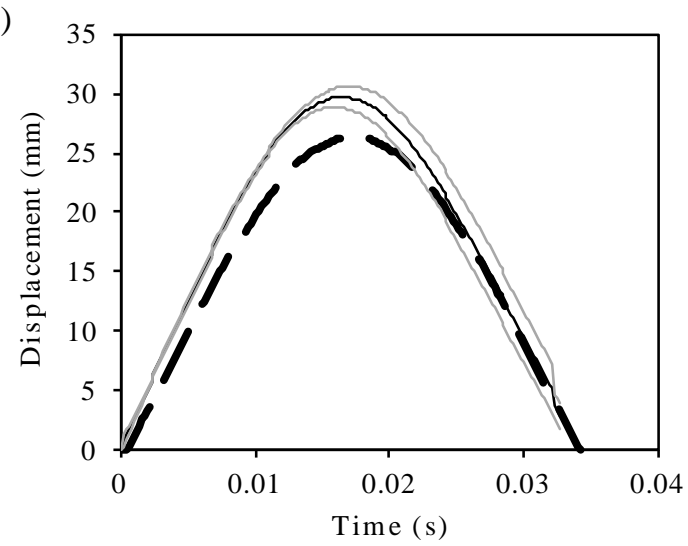

(c)

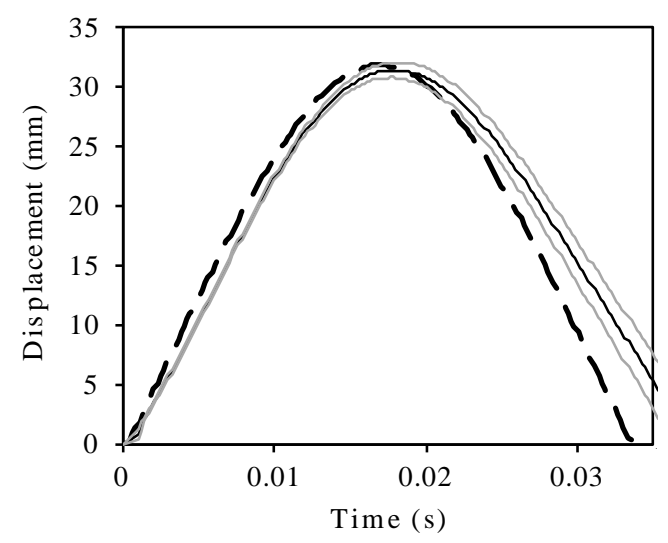

(d)

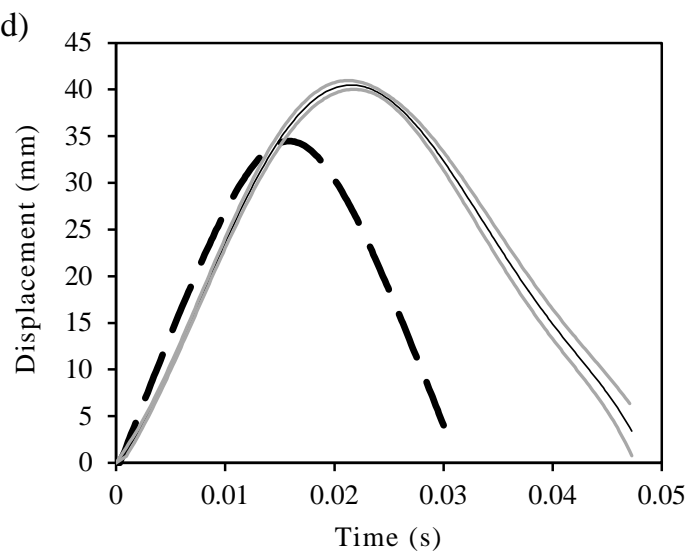

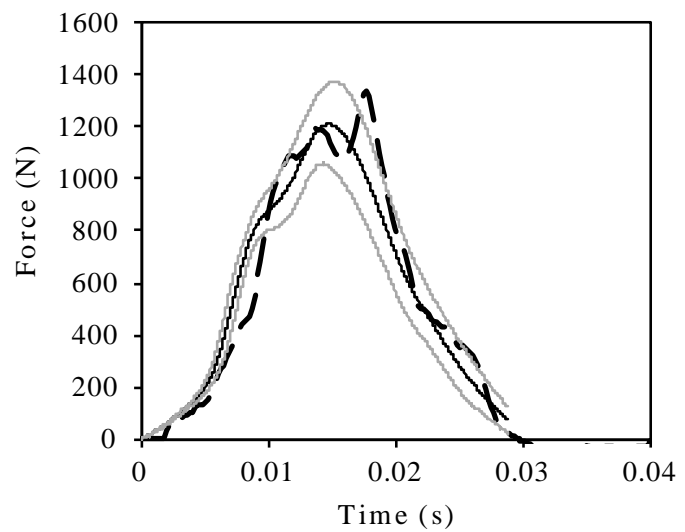
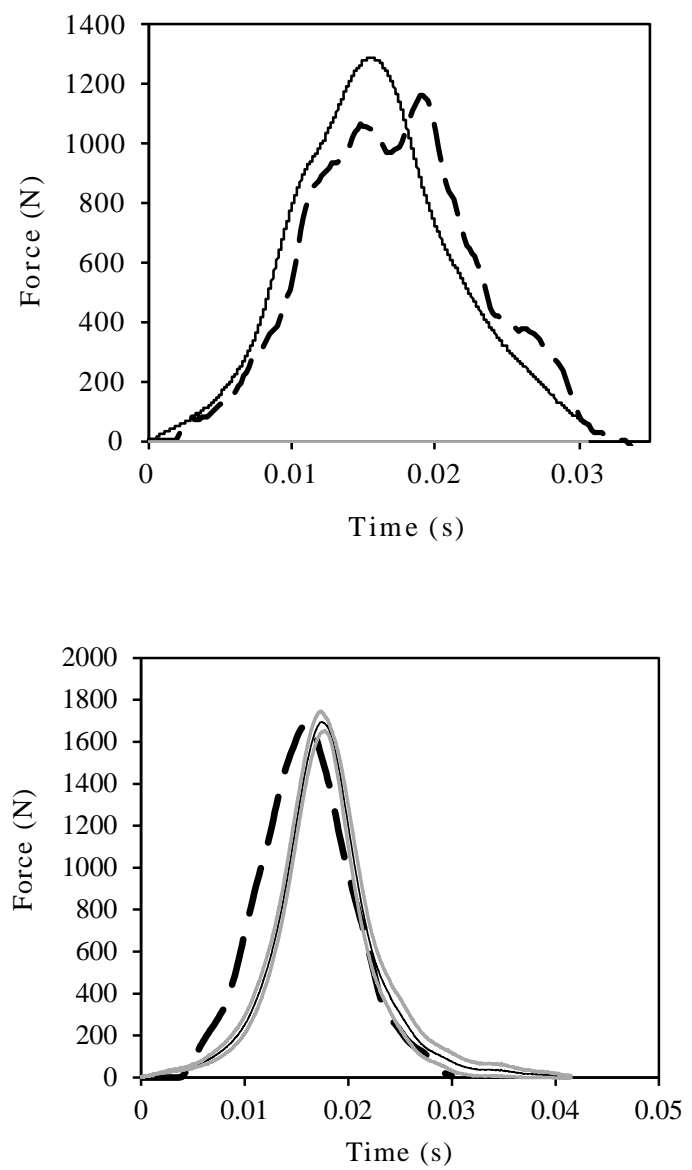

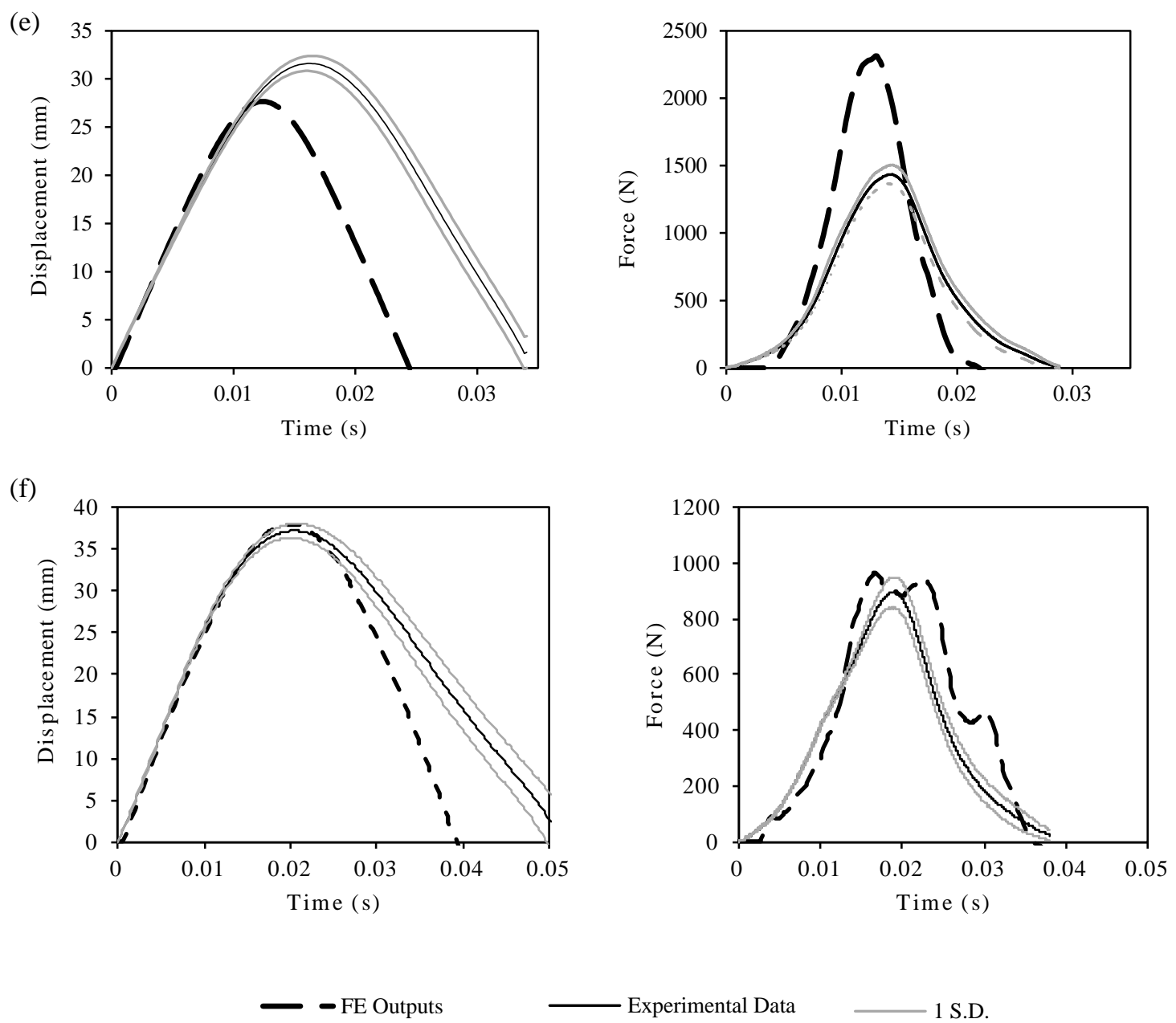
1 S.D.

Figure 15 - Displacement vs. time and force vs. time graphs showing a comparison between experimental results and FE model predictions for: (a) Silastic 3481; (b) Silastic 3483; (c) Silastic 3487; (d) 10\% Gelatin; (e) 20\% Gelatin and (f) PDMS surrogates 


\section{Figure 16}
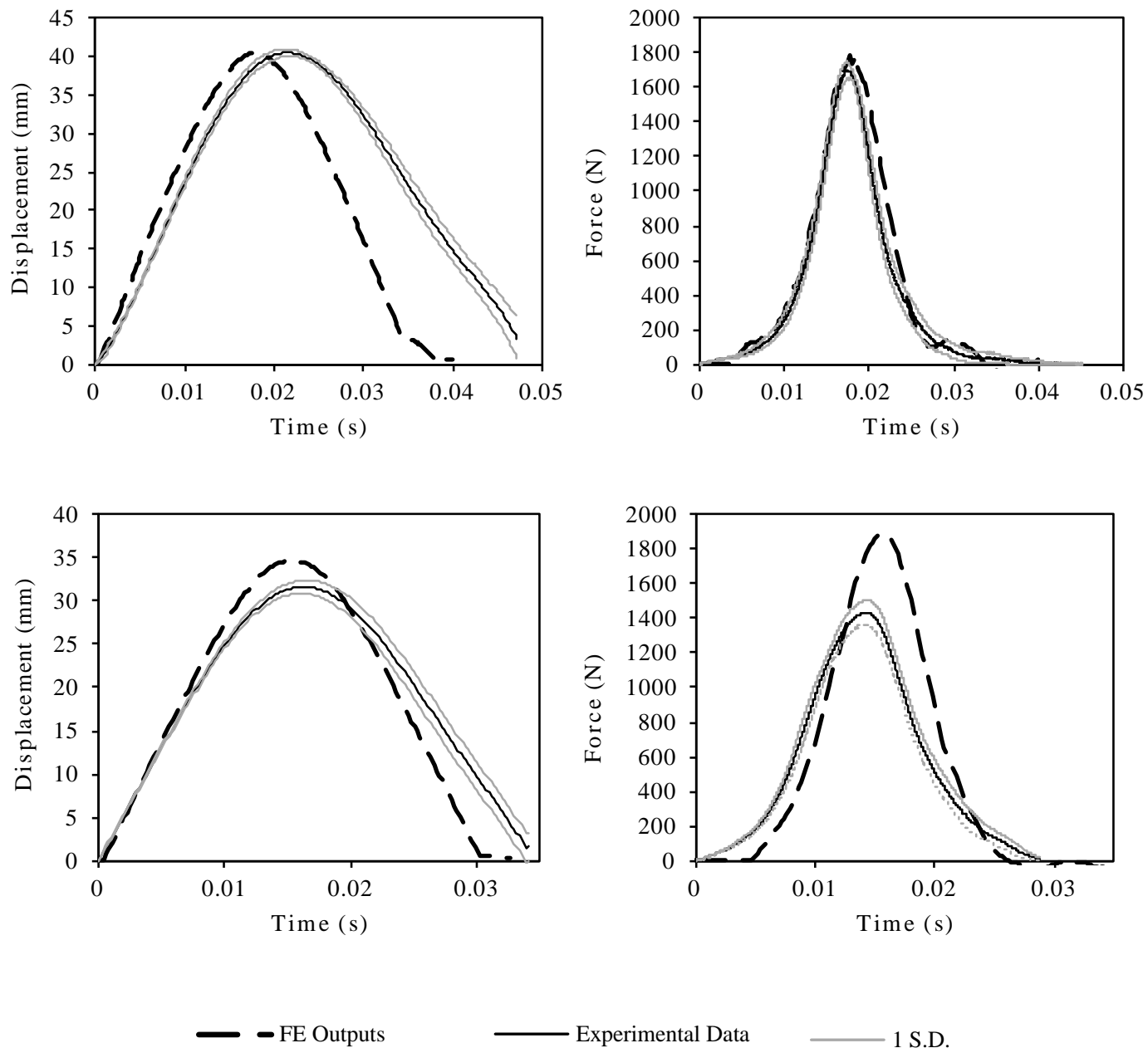

Experimental Data

- 1 S.D.

Figure 16 - Displacement vs. time and force vs. time graphs showing a comparison between experimental results and optimised FE model predictions for: (a) $10 \%$ Gelatin and (b) $20 \%$ Gelatin

\section{Figure 17}
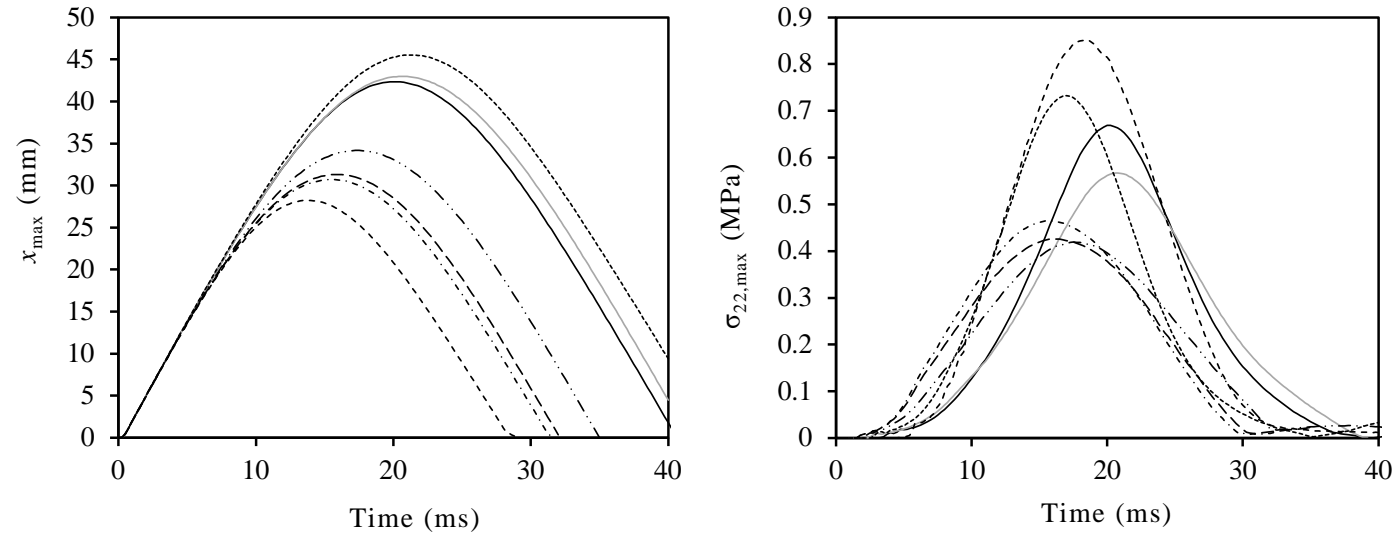

Organic Tissue

PDMS

Silastic 3481

Silastic 3483

Figure 17 - (a) $x_{\max }$ vs. time graph for top surrogate surface; (b) $\sigma_{22, \max }$ vs. time graph on bone surface 


\section{Figure 18}

(a)

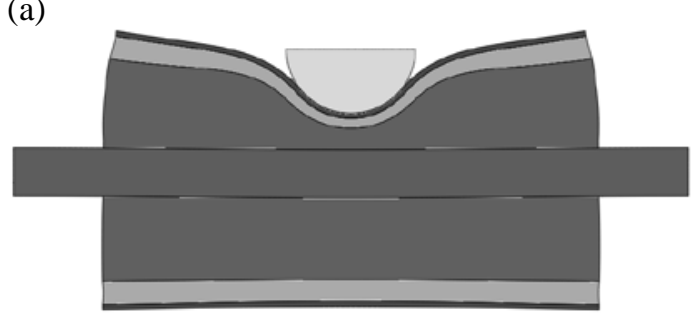

(c)

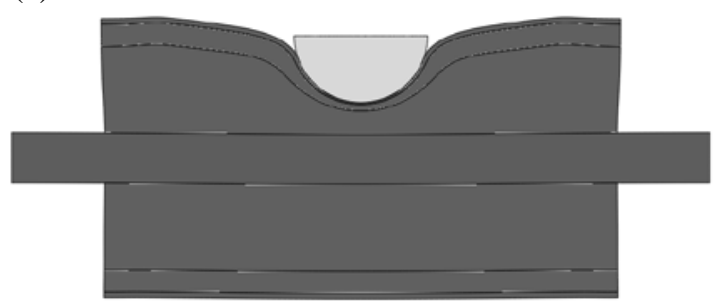

(b)

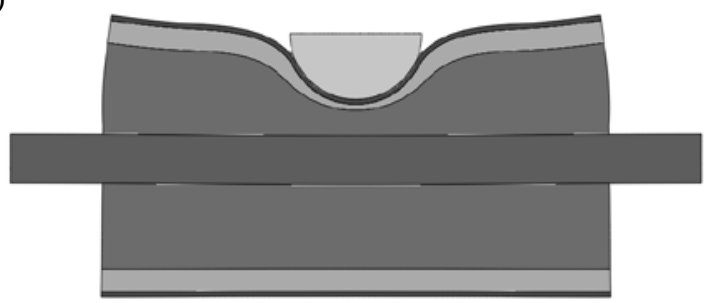

(d)

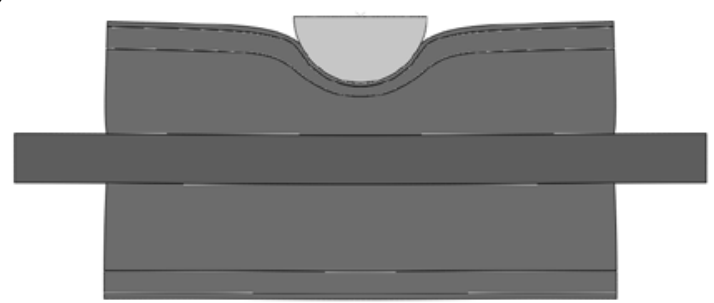

Figure 18 - Images showing surrogate displacement in knee impact simulations in: (a) organic tissues; (b) PDMS; (c) $10 \%$ gelatin; (d) Silastic 3487

\section{Figure 19}

(a)

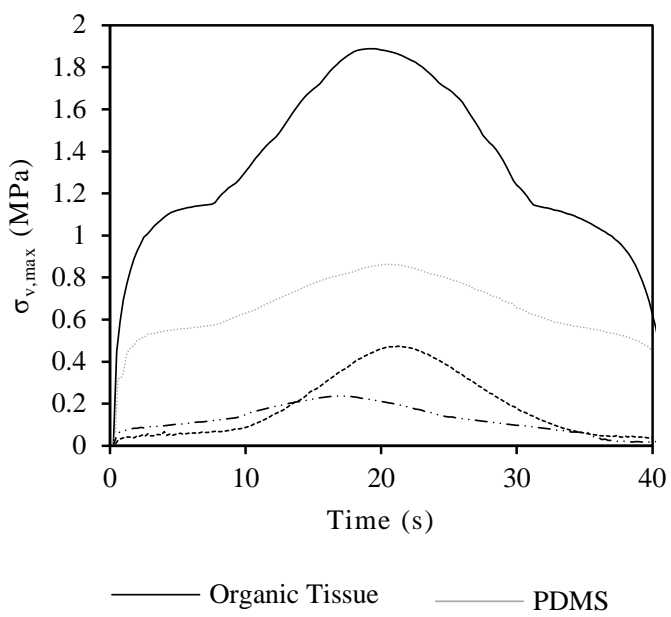

(b)

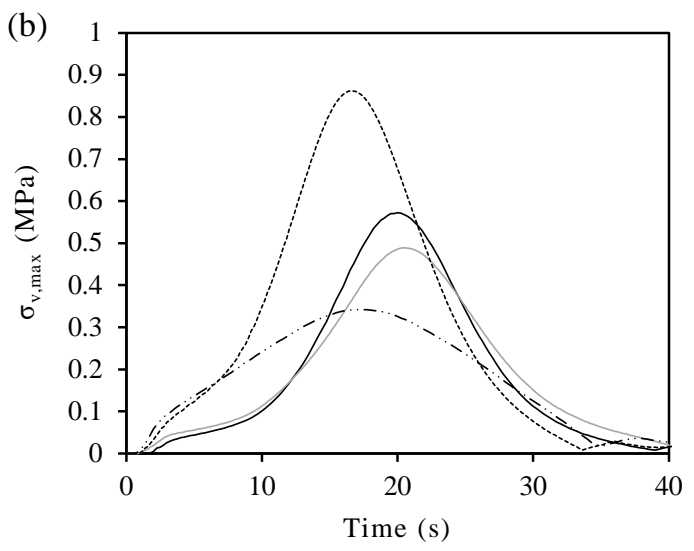

$10 \%$ Gelatin

-..- Silastic 3487

Figure 19 - $\sigma_{\mathrm{v}, \max }$ vs. time graphs for simulant materials on: (a) skin layer surface and (b) muscle layer surface 


\section{Figure 20}

(a)

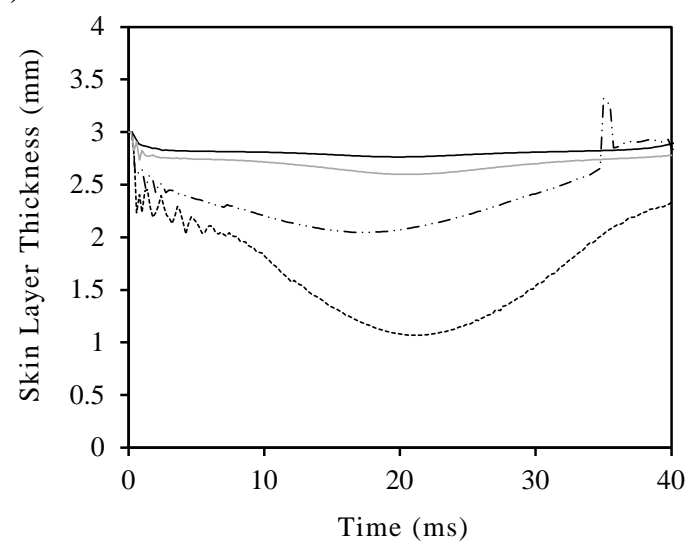

(b)

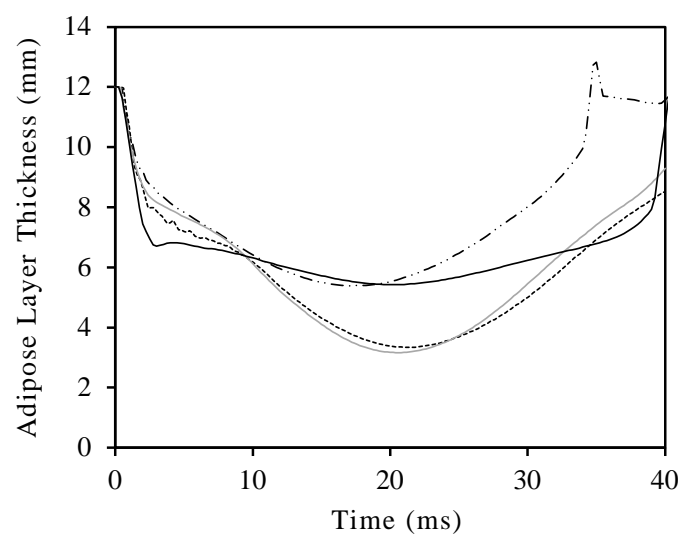

(c)

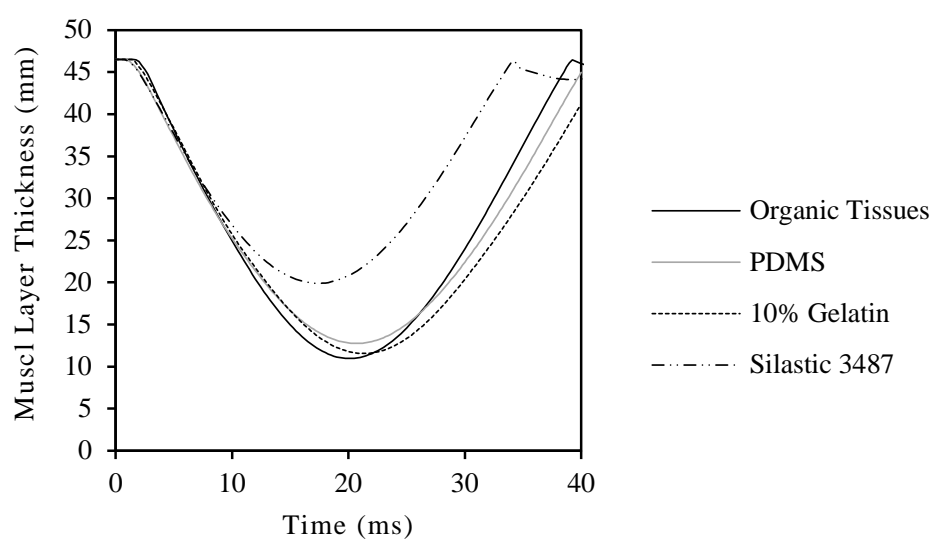

Figure 20 - Tissue layer thicknesses showing responses through the knee impact simulation: (a) skin; (b) adipose; (c) muscle

\section{Figure 21}

(a)

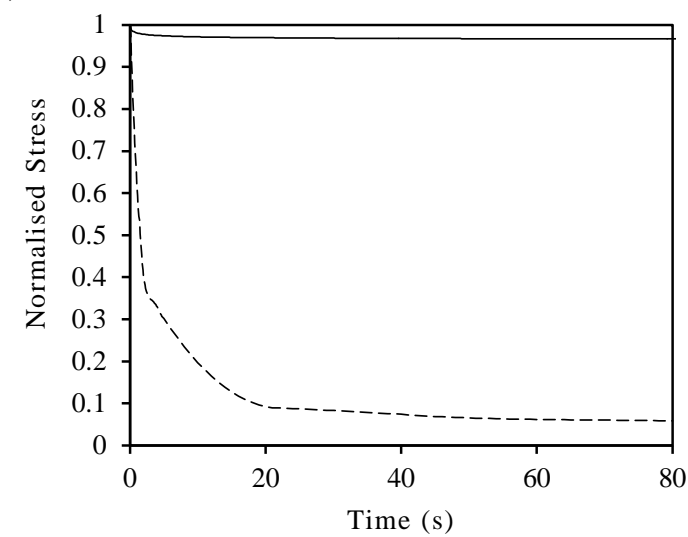

- - - - Organic Tissue (b)

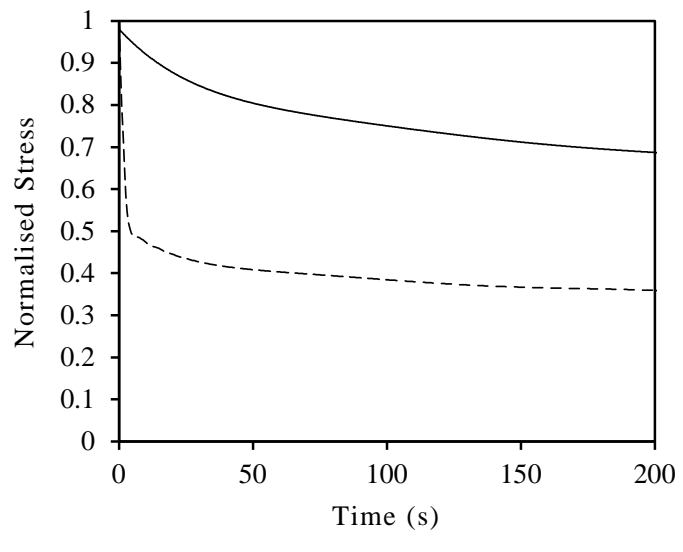

PDMS Simulant

Figure 21 - Normalised stress-time plots showing differences in stress relaxation between PDMS simulants and organic tissues in: (a) skin (Wu et al., 2003); and (b) adipose (Gefen \& Haberman, 2007) tissues 


\section{Table 1}

\begin{tabular}{|c|c|c|c|c|c|c|c|}
\hline \multirow{2}{*}{} & \multicolumn{4}{|c|}{ Part A } & \multicolumn{2}{c|}{ Part B } & \multirow{2}{*}{$\begin{array}{c}\text { Part A:B } \\
\text { Ratio }\end{array}$} \\
\cline { 2 - 5 } & \multicolumn{3}{|c|}{ Polymers } & Catalyst & $\begin{array}{c}\text { H301 Cross } \\
\text { Linker }\end{array}$ & $\begin{array}{c}\text { V31 } \\
\text { Polymer }\end{array}$ & $1: 1$ \\
\hline V46 & V31 & V21 & & $10 \%$ & $90 \%$ & $10: 1$ \\
\hline Adipose & $76.5 \%$ & $9.0 \%$ & $4.5 \%$ & $10 \%$ & $10 \%$ & $90 \%$ & $10 \%$ \\
\hline
\end{tabular}

Table 3 - Part A and B silicone constituent concentrations (\% by mass)

Table 2

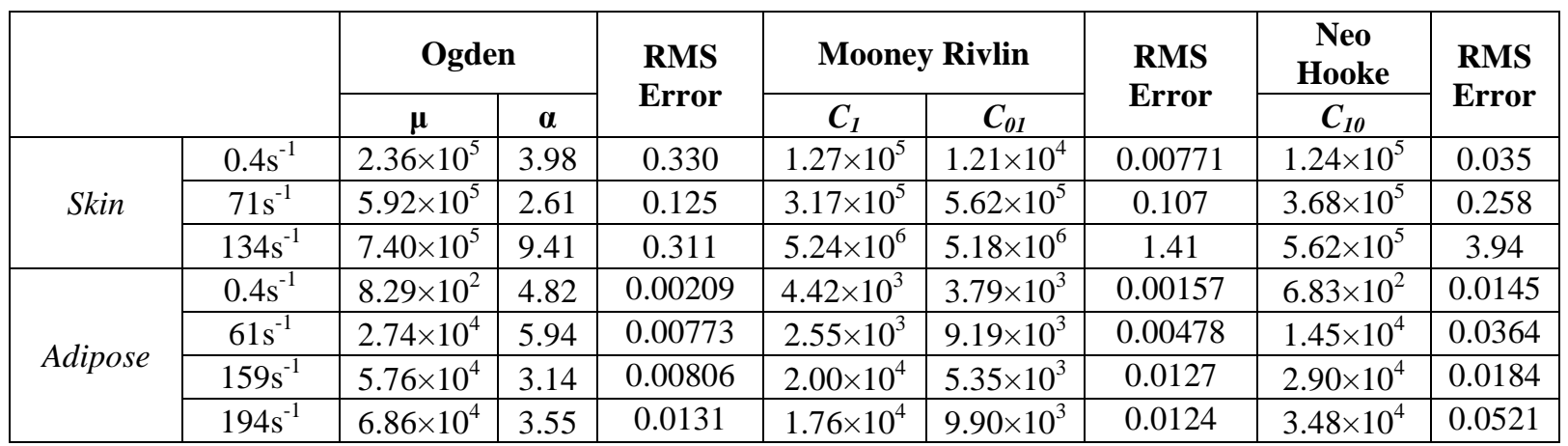

Table 4 - Hyperelastic model coefficients for PDMS skin and adipose tissue simulants

Table 3

\begin{tabular}{|c|c|c|c|}
\hline & $\boldsymbol{i}$ & $\boldsymbol{g ( i )}$ & $\boldsymbol{\tau}(\mathbf{i})$ \\
\hline \multirow{3}{*}{ Skin } & 1 & $2.67 \times 10^{-2}$ & $8.51 \times 10^{-1}$ \\
\cline { 2 - 4 } & 2 & $8.07 \times 10^{-3}$ & $4.04 \times 10^{1}$ \\
\hline \multirow{4}{*}{ Adipose } & 1 & $1.39 \times 10^{-1}$ & $7.51 \times 10^{-5}$ \\
\cline { 2 - 4 } & 2 & $1.70 \times 10^{-1}$ & 3.07 \\
\cline { 2 - 4 } & 3 & $7.41 \times 10^{-2}$ & $7.9 \times 10^{1}$ \\
\hline
\end{tabular}

Table 3 - Prony series coefficients for PDMS skin and adipose tissue simulants

\section{Table 4}

\begin{tabular}{|c|c|c|l|}
\hline & $\boldsymbol{\mu}$ & $\boldsymbol{\alpha}$ & \multicolumn{1}{c|}{$\boldsymbol{\rho}$} \\
\hline Skin & $2.20 \times 10^{6}$ & 12 & 1110 (Mendez \& Keys, 1960; Ward \& Lieber, 2005) \\
\hline Adipose & $1.70 \times 10^{3}$ & 23 & 1100 (Sarvazyan et al., 1998) \\
\hline Relaxed Muscle & $3.63 \times 10^{4}$ & 4.5 & 920 (Fidanza et al, 1954; Farvid, 2005) \\
\hline Cortical Bone & $4.58 \times 10^{9}$ & 25 & 1880 (Yeni et al., 1998) \\
\hline
\end{tabular}

Table 4 - Single term Ogden model coefficients for: skin (Shergold et al., 2006); adipose (Comley \& Fleck, 2012); relaxed muscle (McElhaney, 1966; Song et al., 2007); cortical bone (McElhaney, 1966) and material densities for each organic tissue 


\section{$\underline{\text { Table } 5}$}

\begin{tabular}{|c|c|c|c|c|}
\hline & $\boldsymbol{i}$ & $\boldsymbol{g ( i )}$ & $\boldsymbol{k}(\mathbf{i})$ & $\boldsymbol{\tau}(\mathbf{i})$ \\
\hline \multirow{3}{*}{ Skin } & 1 & $5.01 \times 10^{1}$ & $3.80 \times 10^{-1}$ & $5.73 \times 10^{-1}$ \\
\cline { 2 - 5 } & 2 & $4.44 \times 10^{-1}$ & $5.59 \times 10^{-1}$ & 9.47 \\
\hline \multirow{4}{*}{ Adipose } & 1 & $1.59 \times 10^{-2}$ & 0.00 & $7.83 \times 10^{-5}$ \\
\cline { 2 - 5 } & 2 & $-7.97 \times 10^{-2}$ & 0.00 & $1.17 \times 10^{-3}$ \\
\cline { 2 - 5 } & 3 & $5.89 \times 10^{-1}$ & 0.00 & 1.61 \\
\cline { 2 - 5 } & 4 & $1.25 \times 10^{-1}$ & 0.00 & $7.29 \times 10^{1}$ \\
\hline \multirow{2}{*}{$\begin{array}{c}\text { Relaxed } \\
\text { Muscle }\end{array}$} & 1 & $3.39 \times 10^{-1}$ & 0.00 & 2.37 \\
\cline { 2 - 5 } & 2 & $2.56 \times 10^{-1}$ & 0.00 & $7.02 \times 10^{1}$ \\
\hline
\end{tabular}

Table 5 - Prony series coefficients for organic skin, adipose and relaxed muscle tissues

\section{Table 6}

\begin{tabular}{|c|c|c|c|c|c|c|}
\hline & \multicolumn{3}{|c|}{ Mooney Rivlin Coefficients } & \multicolumn{3}{|c|}{ Prony Series } \\
\hline & $D_{10}$ & $C_{1}$ & $C_{01}$ & $i$ & $g(i)$ & $\tau(i)$ \\
\hline \multirow{3}{*}{$\begin{array}{l}\text { PDMS } \\
\text { Muscle }\end{array}$} & \multirow{3}{*}{-} & \multirow{3}{*}{$-4.00 \times 10^{-3}$} & \multirow{3}{*}{$1.57 \times 10^{4}$} & 1 & $1.28 \times 10^{-1}$ & $3.52 \times 10^{-1}$ \\
\hline & & & & 2 & $5.29 \times 10^{-2}$ & 8.07 \\
\hline & & & & 3 & $3.39 \times 10^{-2}$ & $7.61 \times 10^{1}$ \\
\hline \multirow{5}{*}{$\begin{array}{c}\text { PDMS } \\
\text { Adipose }\end{array}$} & \multirow{3}{*}{ - } & \multirow{3}{*}{$2.55 \times 10^{3}$} & \multirow{3}{*}{$9.19 \times 10^{3}$} & 1 & $1.39 \times 10^{-1}$ & $7.51 \times 10^{-5}$ \\
\hline & & & & 2 & $1.70 \times 10^{-1}$ & 3.07 \\
\hline & & & & 3 & $7.41 \times 10^{-2}$ & $7.9 \times 10^{1}$ \\
\hline & \multicolumn{3}{|c|}{ Ogden Coefficients } & & & \\
\hline & & $\boldsymbol{\mu}$ & $\boldsymbol{\alpha}$ & & & \\
\hline \multirow{2}{*}{$\begin{array}{c}\text { PDMS } \\
\text { Skin }\end{array}$} & \multirow[b]{2}{*}{-} & \multirow{2}{*}{$5.92 \times 10^{5}$} & \multirow{2}{*}{2.61} & 1 & $2.67 \times 10^{-2}$ & $8.51 \times 10^{-1}$ \\
\hline & & & & 2 & $8.07 \times 10^{-3}$ & $4.04 \times 10^{1}$ \\
\hline
\end{tabular}

Table 6 - Prony series coefficients for organic skin, adipose and relaxed muscle tissues 


\section{Table 7}

\begin{tabular}{|c|c|c|c|c|c|c|c|}
\hline & \multicolumn{3}{|c|}{ Mooney Rivlin Coefficients } & \multicolumn{3}{|c|}{ Prony Series } \\
\hline & & $D_{10}$ & $C_{1}$ & $C_{01}$ & $\boldsymbol{i}$ & $g(i)$ & $\tau(i)$ \\
\hline \multirow{9}{*}{ Silastic } & \multirow{3}{*}{3481} & \multirow{3}{*}{-} & \multirow{3}{*}{$6.11 \times 10^{4}$} & \multirow{3}{*}{$1.35 \times 10^{4}$} & 1 & $6.17 \times 10^{-2}$ & $1.80 \times 10^{-1}$ \\
\hline & & & & & 2 & $3.85 \times 10^{-2}$ & 5.55 \\
\hline & & & & & 3 & $3.30 \times 10^{-2}$ & $9.61 \times 10^{1}$ \\
\hline & \multirow{3}{*}{3483} & \multirow{3}{*}{-} & \multirow{3}{*}{$7.65 \times 10^{4}$} & \multirow{3}{*}{$7.91 \times 10^{2}$} & 1 & $5.02 \times 10^{-2}$ & $2.18 \times 10^{-1}$ \\
\hline & & & & & 2 & $2.87 \times 10^{-2}$ & 8.62 \\
\hline & & & & & 3 & $2.60 \times 10^{-2}$ & $9.00 \times 10^{1}$ \\
\hline & \multirow{3}{*}{3487} & \multirow{3}{*}{-} & \multirow{3}{*}{$5.31 \times 10^{4}$} & \multirow{3}{*}{$1.59 \times 10^{3}$} & 1 & $5.52 \times 10^{-2}$ & $2.32 \times 10^{-1}$ \\
\hline & & & & & 2 & $3.51 \times 10^{-2}$ & 8.80 \\
\hline & & & & & 3 & $3.92 \times 10^{-2}$ & $8.81 \times 10^{1}$ \\
\hline & & \multicolumn{3}{|c|}{ Ogden Coefficients } & & & \\
\hline & & $\mu$ & $\alpha$ & 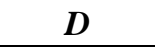 & & & \\
\hline \multirow{4}{*}{$\begin{array}{c}\text { Ballistics } \\
\text { Gelatin }\end{array}$} & \multirow{2}{*}{$10 \%$} & \multirow{2}{*}{$2.52 \times 10^{4}$} & \multirow{2}{*}{2.93} & \multirow{2}{*}{$2.26 \times 10^{5}$} & 1 & $2.27 \times 10^{-1}$ & 1.83 \\
\hline & & & & & 2 & $3.88 \times 10^{-1}$ & $8.16 \times 10^{1}$ \\
\hline & \multirow{2}{*}{$20 \%$} & \multirow{2}{*}{$1.72 \times 10^{4}$} & \multirow{2}{*}{-6.08} & \multirow{2}{*}{$3.29 \times 10^{-5}$} & 1 & $1.56 \times 10^{-1}$ & 1.80 \\
\hline & & & & & 2 & $3.89 \times 10^{-1}$ & $9.39 \times 10^{1}$ \\
\hline
\end{tabular}

Table 7- Hyperelastic Mooney-Rivlin and Ogden model coefficients and viscoelastic Prony series coefficients for single material simulants

\section{Table 8}

\begin{tabular}{|c|c|c|c|c|c|c|c|c|c|c|c|c|}
\hline & \multicolumn{2}{|c|}{$x_{\max }(\mathrm{mm})$} & \multirow{2}{*}{$\begin{array}{c}\% \\
\text { Error }\end{array}$} & \multicolumn{2}{|c|}{$t_{x}(s)$} & \multirow{2}{*}{$\begin{array}{c}\% \\
\text { Error }\end{array}$} & \multicolumn{2}{|c|}{$R F(N)$} & \multirow{2}{*}{$\begin{array}{c}\% \\
\text { Error }\end{array}$} & \multicolumn{2}{|c|}{$t_{r f}(s)$} & \multirow{2}{*}{$\begin{array}{c}\% \\
\text { Error }\end{array}$} \\
\hline & Exp. & $F E$ & & Exp. & $F E$ & & Exp. & $F E$ & & Exp. & $F E$ & \\
\hline $\begin{array}{c}\text { PDMS } \\
\text { Silicones }\end{array}$ & 37.2 & 38.0 & +2.04 & 0.0204 & 0.020 & -1.81 & 867 & 964 & 7.72 & 0.019 & 0.0166 & -12.0 \\
\hline $10 \% \mathrm{Gel}$ & 40.5 & 40.4 & -0.20 & 0.0215 & 0.0178 & -17.1 & 1694 & 1786 & 5.38 & 0.0174 & 0.0178 & 2.07 \\
\hline $20 \% \mathrm{Gel}$ & 31.6 & 34.7 & 9.78 & 0.0165 & 0.0154 & -6.55 & 1435 & 1885 & 31.3 & 0.0143 & 0.0158 & 9.89 \\
\hline $\begin{array}{c}\text { Silastic } \\
3481\end{array}$ & 26.4 & 25.6 & -2.77 & 0.0142 & 0.0126 & -11.6 & 1526 & 1754 & +14.9 & 0.0130 & 0.0129 & -0.99 \\
\hline $\begin{array}{c}\text { Silastic } \\
3483\end{array}$ & 30.0 & 26.3 & -11.2 & 0.0165 & 0.0172 & 4.37 & 1210 & 1335 & 10.3 & 0.0147 & 0.0176 & 19.8 \\
\hline $\begin{array}{c}\text { Silastic } \\
3487\end{array}$ & 31.4 & 31.8 & 1.27 & 0.0180 & 0.017 & -5.35 & 1288 & 1160 & -9.89 & 0.0155 & 0.0192 & 24.2 \\
\hline
\end{tabular}

Table 8 - Comparison of peak displacement $\left(x_{\max }\right)$, time to peak displacement $\left(t_{\max }\right)$ force $(\mathrm{RF})$, time to peak force $\left(t_{r f}\right)$ measurements between experimental data and FE model predictions

\section{Table 9}

\begin{tabular}{|c|c|c|c|c|}
\hline \multirow{2}{*}{} & \multicolumn{2}{|c|}{ Displacement } & \multicolumn{2}{c|}{ Bone Stress } \\
\cline { 2 - 5 } & $x_{\max }(\mathrm{mm})$ & $t_{x}(\mathrm{~ms})$ & $\sigma_{22, \max }(\mathrm{MPa})$ & $t_{\sigma}(\mathrm{ms})$ \\
\hline Organic Tissues & 42.3 & 20.0 & 0.669 & 20.0 \\
\hline PDMS Silicones & $42.9(-1.42 \%)$ & $20.6(+3.00 \%)$ & $0.567(-15.2 \%)$ & $20.8(+4.00 \%)$ \\
\hline $10 \% \mathrm{Gel}$ & $45.5(+7.57 \%)$ & $21.2(+6.00 \%)$ & $0.733(9.57 \%)$ & $17.0(-15.0 \%)$ \\
\hline $20 \% \mathrm{Gel}$ & $28.2(-33.3 \%)$ & $13.8(-31.0 \%)$ & $0.852(+27.4 \%)$ & $18.6(-7.00 \%)$ \\
\hline Silastic 3481 & $30.7(-27.4 \%)$ & $15.5(-22.5 \%)$ & $0.465(-30.5 \%)$ & $15.5(-22.5 \%)$ \\
\hline Silastic 3483 & $31.3(-26.0 \%)$ & $16.0(-20.0 \%)$ & $0.426(-36.3 \%)$ & $16.0(-20.0 \%)$ \\
\hline Silastic 3487 & $34.1(-13.5 \%)$ & $17.3(-13.5 \%)$ & $0.419(-37.4 \%)$ & $17.5(-12.5 \%)$ \\
\hline
\end{tabular}


Table 9 - Maximum recorded displacement $\left(x_{\max }\right)$ and bone stress $\left(\sigma_{22, \max }\right)$ values for knee impact simulations $(\%$ difference from organic tissue predictions in brackets) 